\title{
ASPECTOS ANALÍTICOS E REGULATÓRIOS NA DETERMINAÇÃO DE RESÍDUOS DE MACROLÍDEOS EM ALIMENTOS DE ORIGEM ANIMAL POR CROMATOGRAFIA LÍQUIDA ASSOCIADA À ESPECTROMETRIA DE MASSAS
}

\author{
Marcela Sismotto, Jonas Augusto Rizzato Paschoal* e Felix G. R. Reyes \\ Departamento de Ciência de Alimentos, Faculdade de Engenharia de Alimentos, Universidade Estadual de Campinas, 13083-862 \\ Campinas - SP, Brasil
}

Recebido em 25/7/12; aceito em 17/10/12; publicado na web em 20/2/13

\begin{abstract}
ANALYTICAL AND REGULATORY ASPECTS FOR DETERMINATION OF MACROLIDE RESIDUES IN ANIMAL-DERIVED FOODS BY LIQUID CHROMATOGRAPHY ASSOCIATED WITH MASS SPECTROMETRY. This is an overview of LC-MS techniques applied for macrolide determination in food, including sample preparation and method validation, as well as the policies adopted by international agencies regarding their presence in food. Techniques for the analysis of macrolides in food normally include solid phase or liquid-liquid extraction followed by HPLC. UHPLC presents advantages in running time, detectability and solvent consumption. Triple-quadrupoles are the most common analyzers in instruments used for the determination of contaminants in food, but time-of-flight and ion-trap spectrometers have been successfully applied for analyses focusing on the investigation of structural formula or the presence of degradation products.
\end{abstract}

Keywords: macrolides; liquid chromatography; mass spectrometry.

\section{INTRODUÇÃO}

Os antimicrobianos são compostos que inibem o crescimento de determinados microrganismos, podendo ser, de modo geral, utilizados na produção animal para tratar enfermidades (aplicação terapêutica), prevenir contra enfermidades causadas pela presença de organismos patogênicos (aplicação profilática) e melhorar a taxa de crescimento e/ou conversão alimentar (utilizados como promotores de crescimento). Uma grande variedade de substâncias antimicrobianas é usada na produção animal em todo o mundo. A presença de resíduos dessas substâncias em produtos alimentícios é uma questão de grande interesse dos órgãos governamentais responsáveis pela saúde pública e das indústrias de alimentos, pois representa riscos à saúde dos consumidores, ressaltando-se a seleção de formas resistentes de microrganismos, a carcinogenicidade, mutagenicidade, teratogenicidade e a hipersensibilidade. ${ }^{1-6}$ Sendo o Brasil um país de expressiva atividade pecuária no cenário mundial, é fundamental que estejam em vigor programas eficientes que garantam a qualidade de alimentos desta origem. Para atender a essa demanda, é necessário o desenvolvimento de métodos analíticos confiáveis que possibilitem a determinação de medicamentos veterinários em níveis residuais (na ordem de $\mathrm{ng} \mathrm{g}^{-1}$ ), haja vista que são substâncias potencialmente tóxicas para a saúde humana e para o meio ambiente.

Segundo Mellon et al., ${ }^{7}$ estima-se que nos Estados Unidos cerca de $70 \%$ da produção anual de antimicrobianos (considerando um total de 16000 t) tenham sido utilizadas na pecuária com fins não terapêuticos.

Dentre as diferentes classes de antimicrobianos existentes, destacam-se os macrolídeos por serem altamente potentes contra uma grande variedade de bactérias Gram-positivas e Gram-negativas. A Organização Mundial para a Saúde Animal (Office International dés Épizoties - OIE) considera alguns macrolídeos, como a eritromicina, espiramicina, tilmicosina e tilosina, como criticamente importantes na pecuária de bovinos, suínos e aves, já que existem poucos tratamentos alternativos para algumas doenças que atingem estas espécies. ${ }^{8}$

*e-mail: jonaspaschoal@yahoo.com.br

\section{MACROLÍDEOS}

O conhecimento das características físico-químicas dos macrolídeos é muito importante para o desenvolvimento de métodos analíticos que visam a determinação deste grupo de antimicrobianos em alimentos de origem animal. Também é necessário levar em consideração alguns aspectos da biotransformação destes compostos no organismo animal, pois possíveis metabólitos podem ser gerados, podendo também se constituírem em analitos alvos dos métodos analíticos.

Quimicamente, os macrolídeos são moléculas lipofílicas constituídas por uma lactona macrocíclica com 14, 15 ou 16 carbonos ligada a moléculas de açúcares (desosamina, cladinose, micaminose, micarose, micosamina) através de ligações glicosídicas, podendo apresentar caráter básico. Os macrolídeos são classificados em grupos, baseando-se no número de carbonos do grupo lactona. A eritromicina, a roxitromicina e a claritromicina pertencem ao grupo de 14 carbonos; a azitromicina pertence ao grupo de 15 carbonos; enquanto que a espiramicina, josamicina, tilmicosina e tilosina pertencem ao grupo de 16 carbonos. ${ }^{9}$ A azitromicina, a claritromicina e a roxitromicina são derivadas da eritromicina. A tilmicosina é sintetizada a partir da tilosina. Em geral, os macrolídeos apresentam $\mathrm{pK}_{\mathrm{a}}$ entre 7,1 e 9,9. ${ }^{10}$ Alguns macrolídeos são sensíveis a baixo $\mathrm{pH}$ e sofrem degradação em condições ácidas. ${ }^{1}$

A eritromicina é um dos macrolídeos mais importantes. Produzida através de fermentação por uma cepa do Streptomyces erythaeus, seu componente predominante é a eritromicina A. Dependendo das condições de fermentação e purificação, outras substâncias como as eritromicinas B, C, D, E e F, a $\mathrm{N}$-dimetileritromicina e o $\mathrm{N}$-óxido de eritromicina $\mathrm{A}$ podem estar presentes em pequenas quantidades (Figura 1). ${ }^{9,11,12}$

A eritromicina é biotransformada através da perda de uma molécula de água, resultando em um produto de biodegradação sem atividade antimicrobiana.

A espiramicina é produzida por algumas cepas de Streptomyces ambofaciens e consiste de uma mistura natural de três componentes: a espiramicina I, II e III, dos quais a espiramicina I está presente em 


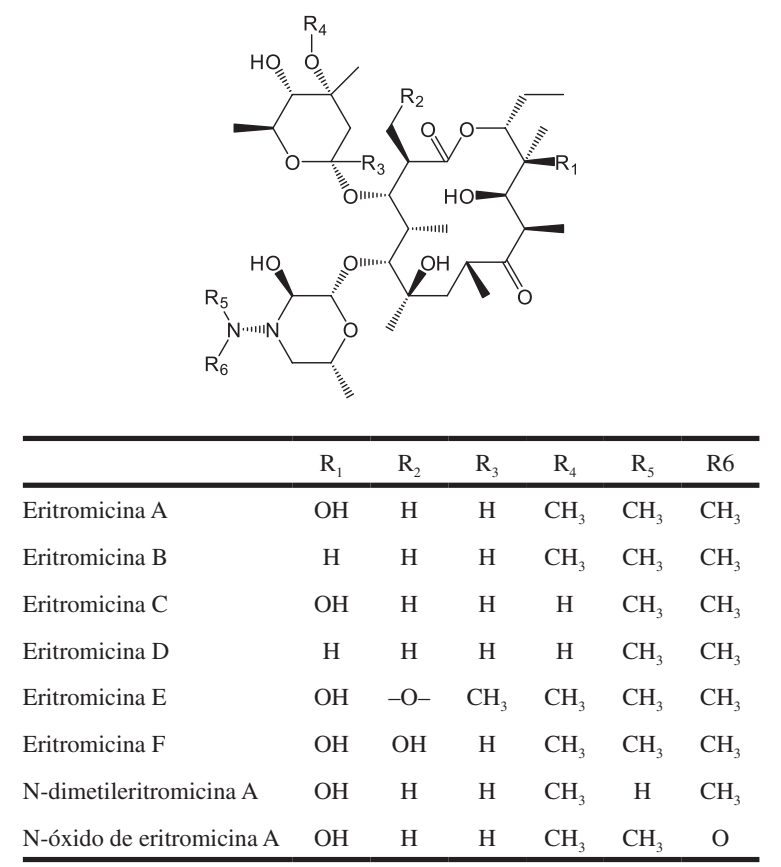

Figura 1. Estrutura molecular da eritromicina e seus compostos relacionados

maior quantidade. ${ }^{13}$ Um de seus produtos de biodegradação é a neoespiramicina, cuja atividade antimicrobiana corresponde a $88 \%$ da atividade da espiramicina. Segundo a regulamentação da Comissão Europeia, os resíduos marcadores para a espiramicina são a espiramicina I e neoespiramicina para gado e frango e a espiramicina I para suínos. ${ }^{13}$ A Figura 2 mostra as estruturas moleculares da espiramicina e da neoespiramicina.

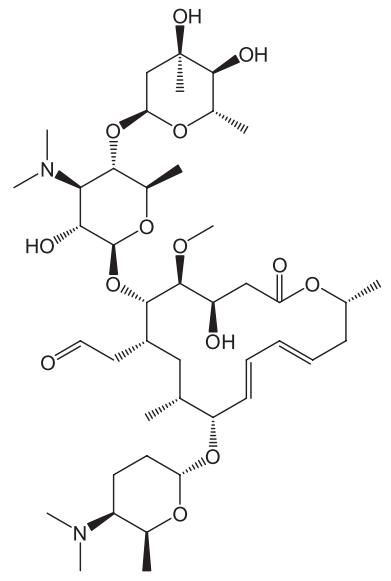

(a)

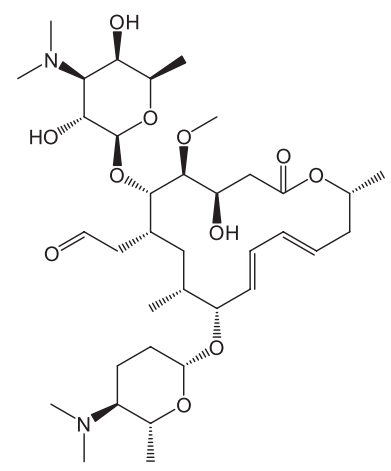

(b)
Figura 2. Estruturas moleculares da espiramicina (a) e da neoespiramicina (b)

A tilosina é produzida pelo Streptomyces fradiae e é ativa contra algumas bactérias Gram-positivas, Gram-negativas e micoplasmas Gram-positivos, sendo usada exclusivamente na medicina veterinária. $\mathrm{O}$ composto de maior predominância é a tilosina $\mathrm{A}$, mas quantidades variáveis de desmicosina (tilosina $\mathrm{B}$ ), macrocina (tilosina C) e relomicina (tilosina D) também estão presentes em sua composição (Figura 3). A atividade antimicrobiana é principalmente devida à tilosina $\mathrm{A}$, enquanto que as tilosinas B, C e D têm em torno de 50, 70 e $30 \%$ da atividade antimicrobiana da tilosina $\mathrm{A}$, respectivamente. ${ }^{14} \mathrm{~A}$ tilosina A degrada-se gradualmente à tilosina $\mathrm{B}$ em condições ácidas e, apesar de ser considerada o resíduo marcador, a presença dos outros tipos de tilosina pode levar a uma diferença de $15 \%$ na quantificação de seus resíduos totais. ${ }^{14,15}$

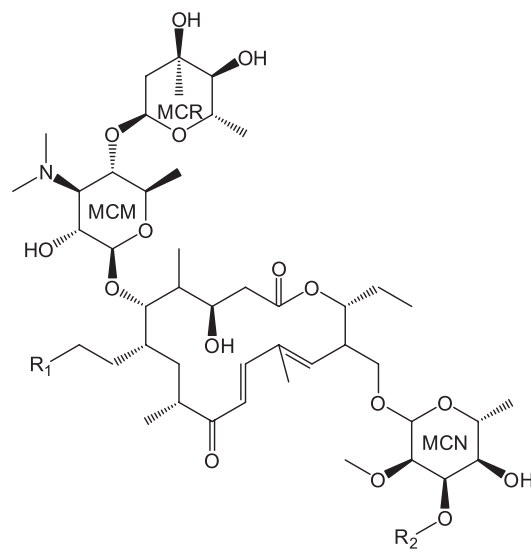

\begin{tabular}{|c|c|c|c|}
\hline & $\mathrm{R}_{1}$ & $\mathrm{R}_{2}$ & MCR \\
\hline Tilosina A & $\mathrm{CHO}$ & $\mathrm{CH}_{3}$ & Presente \\
\hline Tilosina B & $\mathrm{CHO}$ & $\mathrm{CH}_{3}$ & Ausente \\
\hline Tilosina C & $\mathrm{CHO}$ & $\mathrm{H}$ & Presente \\
\hline Tilosina D & $\mathrm{CH}_{2} \mathrm{OH}$ & $\mathrm{CH}_{3}$ & Presente \\
\hline
\end{tabular}

$\mathrm{MCN}=$ micinose $; \mathrm{MCM}=$ micaminose $; \mathrm{MCR}=$ micarose

Figura 3. Estruturas moleculares da tilosina A e seus compostos relacionados

A tilmicosina é um macrolídeo semissintético derivado da tilosina e apresenta espectro de ação similar a esta. A Figura 4 mostra a estrutura molecular da tilmicosina. ${ }^{13}$

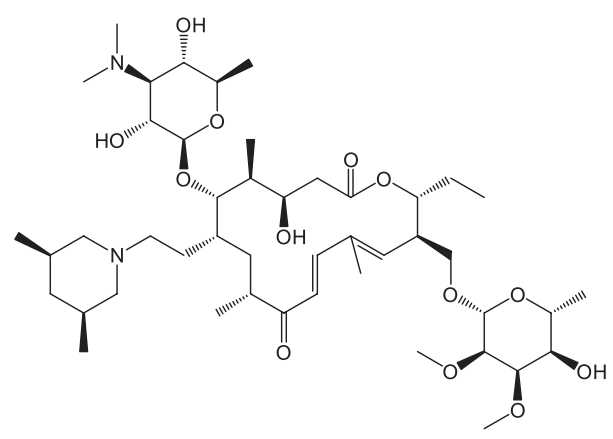

Figura 4. Estrutura molecular da tilmicosina

\section{MÉTODOS ANALÍTICOS}

\section{Preparo de amostras e extração dos macrolídeos}

O emprego de cromatografia líquida de alta eficiência (High Performance Liquid Chromatography - HPLC) associada à espectrometria de massas (Mass Spectrometry - MS) geralmente requer um preparo de amostra menos elaborado quando comparado à HPLC com detecção ótica, uma vez que os instrumentos empregados são dotados do recurso de cromatograma de massa extraída, que só não garante a seletividade cromatográfica quando ocorre coeluição com um interferente de mesma massa molar do analito. No entanto, não se deve subestimar a importância da etapa de preparo de amostras para a detecção e quantificação de resíduos de medicamentos veterinários por espectrometria de massas em alimentos, já que a complexidade deste tipo de matriz pode dificultar o procedimento analítico devido à supressão de íons, à formação de adutos e outros efeitos. ${ }^{16}$

$\mathrm{O}$ tratamento de matrizes alimentícias geralmente requer procedimentos para a desproteinização, remoção de gordura e açúcares. 
As técnicas mais utilizadas para estes fins são a extração em fase sólida (Solid Phase Extraction - SPE) e a extração líquido-líquido (Liquid-Liquid Extraction - LLE). No entanto, a extração líquida pressurizada (Pressurized Liquid Extraction - PLE), a microextração em fase sólida (Solid Phase Micro Extraction - SPME), a dispersão da matriz em fase sólida (Matrix Solid Phase Dispersion - MSPD) e a simples diluição também têm sido empregadas. O tipo de preparo de amostra depende principalmente dos macrolídeos em questão, das matrizes envolvidas e dos objetivos específicos da análise.

Geralmente, a SPE é realizada passando-se extratos aquosos através de cartuchos que contêm de 30 a $500 \mathrm{mg}$ de fase estacionária, sob vácuo, para auxiliar no controle da eluição do solvente de extração. Esta técnica apresenta vantagens como a limpeza eficiente dos extratos, a remoção de interferentes e a redução do efeito matriz. Além disso, esta técnica permite a concentração dos analitos, melhorando a sensibilidade do método. Como os macrolídeos apresentam características lipofílicas, são normalmente retidos em fases estacionárias hidrofóbicas e, após lavagem com água ou tampão, são eluídos com poucos mililitros de um solvente orgânico apropriado, como metanol ou acetonitrila, que podem ser evaporados e concentrados a um volume adequado para injeção no sistema cromatográfico. ${ }^{17}$ Tampões básicos também são frequentemente empregados nesta etapa, devido às características básicas de algumas moléculas de macrolídeos que, assim, permanecem na forma não ionizada durante a extração em fase sólida, o que garante sua afinidade pela fase estacionária.

Algumas fases estacionárias já estudadas para este fim são: balanço hidrofílico-lipofílico (Hidrophilic-Lipophilic Balance - HLB, Waters), Strata- $X^{\circledast}$ (Phenomenex), octadecilsilano $\left(\mathrm{C}_{18}\right)$, sílica derivatizada com 2,3-di-hidroxipropoxipropil (Bond-Elut diol ${ }^{\circledR}$, Varian), troca catiônica com ácido benzenossulfônico (Bond-Elut SCX ${ }^{\circledR}$, Varian). Os cartuchos HLB, constituídos de um sorvente de fase reversa feito com um copolímero de $N$-vinilpirrolidona hidrofílica e divinilbenzeno lipofílico, são normalmente preferidos devido a sua boa capacidade de retenção e à recuperação reprodutível de compostos em uma ampla faixa de polaridade, sejam eles ácidos, básicos ou neutros. Os macrolídeos são bem retidos em cartuchos HLB e permitem a lavagem com até $40 \%$ de metanol sem perdas significativas. ${ }^{18}$ Os cartuchos Strata- $\mathrm{X}^{\circledR}$ são compostos de um polímero de estireno divinilbenzeno com superfície modificada e apresentam funcionalidade similar ao HLB na retenção de macrolídeos.

Na literatura científica encontram-se exemplos onde, para extrair macrolídeos de mel, amostras (5 g) são dissolvidas em tampão fosfato (0,1 M, pH 8); ${ }^{19-22}$ tampão tris (0,1 M, pH 10,5):;3 ou tampão $\mathrm{Na}_{2} \mathrm{CO}_{3} /$ $\mathrm{NaHCO}_{3} \cdot{ }^{14,24}$ Após um tratamento inicial envolvendo filtração e centrifugação para remover lipídeos e resíduos sólidos, os extratos passam por SPE para remover açúcares, pigmentos e compostos fenólicos do mel e para concentrar os macrolídeos. Para a extração de macrolídeos de tecidos animais, ovo e leite, amostras de 1 a 5 g são primeiramente desproteinizadas e desengorduradas. A desproteinização é usualmente realizada com solventes orgânicos, como acetonitrila, em quantidades 3 a 5 vezes superiores à quantidade de amostra. ${ }^{18,19,25-30}$ Os extratos são posteriormente desengordurados com hexano e submetidos à extração em fase sólida, onde ocorre a remoção de interferentes e a concentração dos analitos.

Pode-se citar também a extração de espiramicina e tilosina de ração animal, onde 2,5 g de amostra foram submetidos à extração com $10 \mathrm{~mL}$ da mistura metanol:ácido fórmico a $2 \%$ (70:30 v/v). Uma alíquota de $1 \mathrm{~mL}$ desta solução foi coletada e a ela foram adicionados $9 \mathrm{~mL}$ de água. Esta solução foi aplicada em cartuchos HLB. Os analitos foram eluidos dos cartuchos com $2 \mathrm{~mL}$ de água:acetonitrila 1:1 (v/v). Neste caso, a SPE eliminou a etapa lenta de evaporação do metanol. ${ }^{29,31,32}$ A tilosina forma um complexo com a ureia presente em algumas rações bovinas e, neste caso, utiliza-se a enzima urease para hidrolisar esta substância e liberar a tilosina do complexo, procedimento necessário para o método atingir valores aceitáveis de recuperação e precisão. ${ }^{32}$

A combinação de extração em fase sólida com extração líquido-líquido tem se mostrado efetiva para a extração de macrolídeos. $\mathrm{Na}$ análise de eritromicina em salmões, um tampão de formiato de amônio $(10 \mathrm{mM})$, ao invés de solventes orgânicos, foi utilizado na primeira etapa, que foi seguida de extração em fase sólida com HLB e de extração líquido-líquido com cloreto de metileno. Embora este método elimine as etapas de precipitação de proteínas e remoção de lipídeos antes da extração em fase sólida, a extração líquido-líquido ao fim do preparo de amostra confere uma limpeza efetiva do extrato. ${ }^{33}$ Em outra aplicação, tampão fosfato foi adicionado aos tecidos homogeneizados e a mistura foi particionada com clorofórmio para a extração líquido-líquido, seguida de extração em fase sólida com Bond-Elut $^{\circledR}$ (Varian) diol para extrair eritromicina, tilmicosina e tilosina de tecidos bovinos. ${ }^{34}$

Uma técnica de custo relativamente baixo e ecologicamente correta reportada para extrair tilosina, tilmicosina, espiramicina, eritromicina e eritromicina anidra de iogurte e leite usa a MSPD e água como solvente de extração. Uma amostra de $1,5 \mathrm{~mL}$ (leite) ou $1,5 \mathrm{~g}$ (iogurte) foi dispersa em 5 ou $6 \mathrm{~g}$ de areia, que serviu como material de suporte, e misturada. A mistura foi então empacotada em uma coluna de MSPD e os macrolídeos eluídos com água a $70{ }^{\circ} \mathrm{C}$ acidificada com ácido fórmico a pH 4,6 e o extrato final foi ajustado para $\mathrm{pH} 6$ antes da injeção no sistema LC-MS. ${ }^{35} \mathrm{O}$ método apresentou boa detectabilidade, com limites de detecção abaixo de $\mu \mathrm{g} \mathrm{kg}^{-1}$, muito embora se deva atentar para a questão da instabilidade da eritromicina em condições ácidas.

A simples diluição do extrato antecedendo a injeção cromatográfica pode se mostrar útil em métodos onde se deseja extrair analitos de diferentes classes, com características físico-químicas diferentes, o que representa uma vantagem em relação à SPE, a qual normalmente é utilizada sob um ajuste de condições para se obter maior seletividade. Muito embora a diluição reduza o efeito matriz, este método pode não atingir os limites de detecção e quantificação requeridos. Além disso, uma simples diluição do extrato, sem a complementação do processo com etapas de limpeza do extrato, pode tornar mais frequentes as paradas para manutenção do sistema LC-MS (regeneração e troca da coluna cromatográfica, limpeza da fonte de ionização e lentes do espectrômetro de massas) de modo a garantir a sensibilidade do sistema e a reprodutibilidade das análises. ${ }^{17}$ Como exemplo, para análises de tilosina em mel, $2 \mathrm{~g}$ de amostra foram misturadas e diluídas cinco vezes com uma mistura de água e acetonitrila (70:30, v/v), filtradas e injetadas no sistema LC-MS. Uma válvula de desvio foi utilizada para direcionar o fluxo para o descarte antes e depois da eluição dos analitos, com o objetivo de minimizar a contaminação da fonte de ionização. Um solvente mais apolar (acetato de etila) foi adicionado ao final do gradiente para remover da coluna resíduos de mel que não seriam eluídos com acetonitrila. ${ }^{36,37}$ Em outro caso, macrolídeos e outros antimicrobianos, num total de 19 substâncias, foram extraídos de músculo e fígado de suínos, bovinos e equinos com metanol a 70\%, com posterior diluição em cinco vezes com água e injeção no sistema LC-MS. Este método foi adequado para monitorar os antimicrobianos nestas matrizes e conseguiu detectar macrolídeos com relação sinal/ ruído maior que 8 em concentrações de 50 a $1000 \mu \mathrm{g} \mathrm{kg}^{-1} \cdot{ }^{30} \mathrm{Um}$ terceiro exemplo envolve a análise de eritromicina em trutas, onde $1 \mathrm{~g}$ de amostra foi misturada com água $(1 \mathrm{~mL})$ e o analito foi extraído a partir da adição de $4 \mathrm{~mL}$ de acetonitrila, agitação, sonicação e centrifugação a $10000 \mathrm{~g}$. O sobrenadante foi coletado e o pelete (precipitado) foi ressuspendido em $5 \mathrm{~mL}$ de acetonitrila e agitado, sonicado e centrifugado novamente e o sobrenadante coletado. Os sobrenadantes foram combinados, o extrato foi desengordurado com 
hexano, filtrado e analisado por LC-MS. Deve-se ressaltar que este método visava atingir níveis de concentração a 0,$5 ; 1$ e 1,5 vezes o LMR da eritromicina nos EUA, que é de $200 \mu \mathrm{g} \mathrm{kg}^{-1}{ }^{25}$

Spisso et al. ${ }^{38}$ estabeleceram um método analítico para a determinação simultânea de 3 macrolídeos, 6 ionóforos poliéteres e 1 lincosamida em ovos, empregando um método relativamente simples de extração por solvente. As amostras de ovos (gema e clara) foram homogeneizadas e extraídas com duas porções de $4 \mathrm{~mL}$ de acetonitrila. Depois de repetidos processos de agitação e centrifugação, as misturas foram evaporadas, ressuspendidas para um volume conhecido, seguido de filtração em membrana e injetadas em sistema LC-MS/MS. Os limites de quantificação para todos os analitos foram inferiores a $5,3 \mu \mathrm{g} \mathrm{kg}^{-1}$.

Recentemente Tao et al. ${ }^{39}$ publicaram um método analítico multirresíduos, empregando um mesmo procedimento de extração líquida pressurizada (PLE) para a extração simultânea de 14 macrolídeos e 3 avermectinas de músculo, rim e fígado de bovinos e suínos. A PLE é uma técnica que se baseia no uso de solvente sob pressão e temperatura relativamente altas, porém sem que se alcancem seus pontos críticos, o que implica na expectativa de uma melhora da eficiência do processo de extração quando comparado a processos sob pressão atmosférica e temperatura ambiente. Os autores utilizaram como solvente uma mistura de acetonitrila e metanol $(1: 1, \mathrm{v} / \mathrm{v})$, em temperatura de $60{ }^{\circ} \mathrm{C}$ e pressão de 1500 psi. Concluíram que o procedimento PLE utilizado resultou em um método rápido, simples e robusto, com recuperações acima de $75 \%$ para todos os analitos e, ainda, permitiu a quantificação e confirmação de identidade para os analitos em concentrações entre 4 e 40 vezes os respectivos LMR estabelecidos.

A técnica de PLE também é denominada como extração acelerada com solvente (Accelerated Solvent Extraction - ASE), extração pressurizada com solvente (Pressurized Solvent Extraction - PSE) ou extração pressurizada com fluido (Pressurized Fluid Extraction - PFE).

Em outro trabalho, em que os autores Juan et al. ${ }^{40}$ determinaram simultaneamente 5 antimicrobianos do grupo dos macrolídeos e dois do grupo das lincosamidas em carne e leite bovinos, foi empregado um procedimento PLE em que se utilizou como solvente apenas a acetonitrila, em temperatura de $40^{\circ} \mathrm{C}$ e pressão de 1500 psi. O método permitiu uma recuperação média no processo de extração para todos os analitos em torno de $79 \%$ em leite e $84 \%$ em carne.

\section{Separação cromatográfica}

A separação cromatográfica de macrolídeos baseia-se em suas características lipofílicas, com o uso de colunas de fase reversa. $\mathrm{Na}$ maioria dos casos, são utilizadas colunas convencionais de fase estacionária de sílica porosa ligada a octadecilsilano $\left(\mathrm{C}_{18}\right)$, mas recentemente colunas para cromatografia líquida de ultra eficiência (Ultra High Performance Liquid Chromatography - UHPLC) com partículas inferiores a $2 \mu \mathrm{m}$ de diâmetro têm sido aplicadas na separação destes analitos. As análises por UHPLC são muito mais rápidas, consomem menos solvente, apresentam eficiência mais elevada e detectabilidade cerca de duas a três vezes maiores quando comparada à HPLC. ${ }^{41}$ Diante dessas vantagens, a UHPLC tornou-se uma técnica de separação inovadora que tem crescido em popularidade no meio científico. ${ }^{42}$ Nota-se uma tendência de mudança no emprego de HPLC convencional para alternativas que permitam uma separação cromatográfica mais rápida e eficiente de macrolídeos em matrizes alimentícias, biológicas e ambientais, devido às vantagens mencioadas, seja pelo emprego de UHPLC, seja pelo uso de sistemas convencionais de HPLC com colunas cromatográficas mais curtas e partículas de diâmetros menores (de 2 a 3,5 $\mu \mathrm{m}$ ), ou colunas monolíticas, que possibilitam análises mais rápidas e com melhor eficiência de separação. ${ }^{17,43,44}$
A composição, a concentração de modificadores e o pH da fase móvel são fatores críticos para se aperfeiçoar tanto a separação cromatográfica, quanto a ionização dos macrolídeos. Metanol e acetonitrila são os solventes orgânicos mais utilizados em HPLC e UHPLC, e ácido fórmico ou acético a $0,1 \%$ ou acetato de amônio $10-20 \mathrm{mM}$ são os modificadores mais comuns. ${ }^{17}$ Ácidos carboxílicos perfluorados podem ser eventualmente utilizados como pares iônicos hidrofóbicos para melhorar a forma dos picos cromatográficos. ${ }^{24,45}$ No entanto, sabe-se que pares iônicos podem causar supressão iônica no caso da ionização por eletronebulização (Electrospray Ionization - ESI), devido à pareação iônica durante o processo de ionização na fonte, provocando perdas significativas no sinal analítico, especialmente em compostos que possuem nitrogênio em suas moléculas. Portanto, pares iônicos devem ser evitados sempre que possível na análise de traços de macrolídeos. ${ }^{17}$

\section{Técnicas de detecção}

Métodos analíticos para a determinação de macrolídeos em várias matrizes envolvem HPLC com detecção ótica, eletroquímica, ou associada à espectrometria de massas (LC-MS). ${ }^{9,45,46}$

A detecção por ultravioleta tem sido usada para a determinação de espiramicina, tilosina e tilmicosina devido às suas duplas ligações conjugadas, que servem como cromóforos com pico de absorbância em 232 ou $287 \mathrm{~nm} .{ }^{46}$ A eritromicina e seus derivados semissintéticos não possuem duplas ligações conjugadas e não são bem detectados em baixas concentrações e, ainda que comprimentos de onda de 210 ou 215 $\mathrm{nm}$ tenham sido utilizados para a análise deste grupo de macrolídeos, sua detecção sofre a interferência de outros compostos, inclusive da fase móvel, que também absorvem nestes comprimentos de onda. ${ }^{9} \mathrm{~A}$ detecção por fluorescência com aplicação de derivatização química tem sido usada para melhorar a sensibilidade na quantificação destes compostos. ${ }^{45,47-49}$ Os macrolídeos possuem grupamentos eletroativos e a detecção eletroquímica tem se mostrado eficaz e sensível na detecção de eritromicina e outros macrolídeos..$^{45,50}$ No entanto, quando se deseja determinar e confirmar a identidade de macrolídeos em uma única análise, técnicas de detecção ótica ou eletroquímica não são suficientes. ${ }^{17}$

\section{Espectrometria de massas}

As vantagens da espectrometria de massas para a detecção de macrolídeos em amostras alimentícias residem nas suas características inigualáveis de detectabilidade, seletividade e capacidade de identificação através do fornecimento de informações estruturais. Dentre as possíveis aplicações da espectrometria de massas em análise de macrolídeos estão: o estudo farmacocinético ou da cinética de depleção destes fármacos e o monitoramento de sua eficácia; ${ }^{37,51-55}$ a elucidação estrutural dos macrolídeos, das impurezas e produtos de degradação: ${ }^{11,12,19,56}$ a garantia da segurança dos consumidores através do monitoramento de seus resíduos em alimentos, contribuindo para o comércio internacional de alimentos; $;^{18-20,26-28,57,58}$ a detecção de tilosina e espiramicina em ração animal, já que o uso destes fármacos como promotores de crescimento foi banido na União Europeia, ${ }^{31,59,60} \mathrm{e}$ a investigação da ocorrência de macrolídeos em amostras ambientais. ${ }^{61-64}$

A espectrometria de massas vem sendo largamente utilizada nas áreas biológica e alimentícia devido a algumas características da técnica, tais como: alta detectabilidade - concentrações baixas de substâncias podem ser detectadas e analisadas; baixo volume de amostra - o uso de interfaces apropriadas para pequenos volumes permite que se use quantidade muito pequena de amostras e, possibilidade de associação com técnicas de separação - a utilização de misturas água/solvente na ionização faz com que ela seja ideal para o acoplamento de sistemas de separação como HPLC. ${ }^{65,66}$ 
Todos os termos técnicos relacionados à área de espectrometria de massas que serão aqui apresentados seguem as recomendações do compêndio de nomenclatura da União Internacional de Química Pura e Aplicada (The International Union of Pure and Applied Chemistry - IUPAC) para esse tema, recomendado para a língua portuguesa, conforme o trabalho de Vessecchi et al.. ${ }^{67}$

\section{Ionização}

Das diversas técnicas de ionização em espectrometria de massas, duas têm se destacado: a ionização por eletronebulização (electrospray ionization - ESI) e a ionização química à pressão atmosférica (atmospheric pressure chemical ionization-APCI). Tanto ESI como APCI são técnicas brandas de ionização, que possibilitam a protonação ou a desprotonação de moléculas, o que facilita a identificação dos compostos, sem a obrigatoriedade do uso de bibliotecas de espectros.

A ionização por ESI ocorre ao se aplicar um potencial elétrico ao eluente quando ele percorre o capilar do nebulizador, resultando na emergência de um aerossol de gotas carregadas. Estas gotas sofrem uma redução de tamanho até atingir uma densidade de carga suficiente para permitir que os íons da amostra sejam expulsos da superfície da gota (evaporação iônica). Geralmente, compostos com menos de 1000 Da produzem íons protonados com carga única $\left([\mathrm{M}+\mathrm{H}]^{+}\right)$ no modo positivo ou desprotonados $\left([\mathrm{M}-\mathrm{H}]^{-}\right)$no modo negativo de ionização, dependendo da estrutura do composto. A fonte de ESI pode ser ajustada para fragmentar os íons durante a ionização, de maneira a fornecer informações valiosas sobre a estrutura de analitos de baixa massa molecular. No entanto, em espectrômetros híbridos é mais conveniente promover a fragmentação em uma cela de colisão existente entre dois analisadores, o que permite a confirmação da identidade do composto, já que a relação $\mathrm{m} / \mathrm{z}$ do íon precursor é conhecida. ${ }^{68} \mathrm{~A}$ ESI é aplicável a compostos com polaridade média a alta e, por isso, tem se tornado a técnica padrão no interfaceamento entre sistemas de cromatografia líquida e espectrômetros de massas. ${ }^{69}$

Na ionização por APCI a amostra é evaporada em um nebulizador aquecido antes de emergir a um plasma constituído de íons do solvente, gerados na fonte por uma descarga corona. A transferência ou abstração de prótons ocorre entre os íons do solvente e as substâncias presentes na amostra. A habilidade de operar com fases móveis $100 \%$ orgânicas ou $100 \%$ aquosas a vazões de até $2 \mathrm{~mL} \mathrm{~min}^{-1}$ torna a APCI uma técnica ideal para uso com uma grande variedade de colunas cromatográficas com fases estacionárias polares ou apolares. ${ }^{68}$ Apesar da predominância do uso de ESI na análise de macrolídeos por LCMS, a APCI tem sido usada em algumas aplicações e demonstrado vantagens com relação à redução do efeito matriz. ${ }^{70-72}$

Especialmente quando se trata de fontes ESI, o efeito matriz deve ser considerado em análises quantitativas por LC-MS. Os componentes da matriz podem tanto melhorar como suprimir os sinais dos analitos, e seu efeito pode variar de amostra para amostra. O efeito matriz pode ser estimado comparando-se o sinal dos analitos em solvente com seu respectivo sinal na presença da matriz, através da adição de seus padrões analíticos no extrato, após todo o processo de tratamento de amostra. ${ }^{73}$

O uso de padrões internos contendo isótopos estáveis (como deutério), curvas analíticas com a matriz (matrix-matched) e a adição de padrão são as abordagens mais comuns para compensar o efeito matriz e melhorar a exatidão do método. Como existem poucos padrões de macrolídeos deuterados no mercado, a quantificação através da curva analítica na matriz (matrix matched calibration), com ou sem a adição de um análogo químico como padrão interno como, por exemplo a roxitromicina, tem sido a abordagem mais usada. ${ }^{17}$ Apesar de efetiva, esta técnica é trabalhosa, já que todo o preparo de amostra se faz necessário a cada replicata de preparação dos padrões para a construção da curva analítica. ${ }^{61}$
Os macrolídeos contêm nitrogênio em suas moléculas e são facilmente protonáveis a íons com carga simples, dupla ou tripla, em fontes ESI no modo positivo. ${ }^{17} \mathrm{O}$ número de cargas possíveis de serem acomodadas nas moléculas está relacionado ao número de nitrogênios presentes nas mesmas. Moléculas com um nitrogênio, como eritromicina e tilosina formam apenas íons monoprotonados $\left([\mathrm{M}+\mathrm{H}]^{+}\right)$. Espiramicina, neoespiramicina, tilmicosina e roxitromicina, que contêm dois átomos de nitrogênio em suas moléculas, formam também íons com dupla carga $\left([\mathrm{M}+2 \mathrm{H}]^{2+}\right)$. Tanto íons monoprotonados quanto com dupla carga têm sido utilizados para aquisição de dados na análise de macrolídeos. , $52,74^{2}$

\section{Espectrômetros de massas}

Os espectrômetros de massas mais utilizados para análise de macrolídeos são os com analisadores de massas do tipo quadrupolo simples (Q), o triplo-quadrupolo (QqQ), quadrupolo-armadilha de íons (Quadrupole-Ion Trap - QIT), quadrupolo-armadilha linear de íons (Quadrupole-Linear Ion Trap-QLIT), tempo de voo (Time-ofFlight - ToF) e quadrupolo-tempo de voo (QToF). Cada um deles apresenta diferentes performances, funções, vantagens e desvantagens que serão brevemente discutidas a seguir.

\section{Quadrupolo simples $(Q)$}

Consiste em quatro hastes metálicas hiperbólicas paralelas. Seu mecanismo de funcionamento se dá através da aplicação de uma corrente elétrica específica em cada uma delas e da imposição de uma radiofrequência, que criam um campo elétrico capaz de estabelecer uma trajetória para íons com razão massa/carga $(\mathrm{m} / \mathrm{z})$ específica, funcionando, então, como um "filtro de massa". O quadrupolo simples pode operar no modo de varredura total (full scan mode) ou de monitoramento de íon selecionado (selected ion monitoring). Apesar de ter aplicabilidade demonstrada na detecção e quantificação de macrolídeos, a falta de seletividade na fragmentação dos íons precursores deste tipo de espectrômetro fez com que fosse substituído por espectrômetros de massas conjugados ou com melhor resolução em massa. ${ }^{75}$

\section{Triplo quadrupolo}

Este é, sem dúvida, o analisador de massas mais usado na análise de resíduos de macrolídeos devido ao seu desempenho incomparável na quantificação, no que diz respeito à faixa dinâmica, à repetibilidade e à sensibilidade. É composto por um primeiro quadrupolo (Q1), uma cela de colisão (Q2) e o terceiro quadrupolo (Q3), podendo ser operado em quatro modos com dissociação induzida por colisão (Collision Induced Dissociation - CID): varredura do íon produto (product ion scan) - consiste em selecionar um íon precursor com uma dada razão $\mathrm{m} / \mathrm{z}$ e determinar todos os íons produtos resultantes da dissociação; varredura do íon precursor (precursor ion scan) - consiste na escolha de um íon produto para determinar seu íon precursor. Requer que o íon produto seja focalizado no terceiro quadrupolo, enquanto o primeiro rastreia o íon de razão $\mathrm{m} / \mathrm{z}$ do precursor, assim, todos os íons precursores que produzam íons daquela razão $\mathrm{m} / \mathrm{z}$ serão detectados; varredura de perda neutra (neutral loss) - consiste em selecionar um fragmento neutro e detectar todas as reações que levariam à perda deste fragmento. Requer que os dois analisadores procedam à varredura concomitantemente, com uma diferença de $\mathrm{m} / \mathrm{z}$, constante entre eles e, monitoramento de reações selecionadas (Selected Reaction Monitoring - SRM) - consiste em selecionar uma reação de fragmentação. Tanto o primeiro quanto o segundo analisador são focalizados nas razões $\mathrm{m} / \mathrm{z}$, selecionadas, não havendo varredura, $\mathrm{o}$ que aumenta a sensibilidade para o monitoramento, associada ao aumento na seletividade. ${ }^{76}$ 
O modo mais comumente utilizado na quantificação de macrolídeos é o SRM. Em geral, faz-se uma primeira aquisição com o padrão da substância em questão no modo de varredura do íon produto, para selecionar as transições SRM que serão usadas na análise por LC-MS. Existe um consenso entre os vários pesquisadores sobre as transições avaliadas, no entanto, há diferenças nas abundâncias relativas entre os íons, devido às diferenças no desenho dos espectrômetros entre os fabricantes, ainda que sejam do mesmo tipo.

O modo de varredura do íon precursor pode ser particularmente útil para identificar contaminantes em matrizes complexas como os alimentos. Em um caso específico, este tipo de análise propiciou a identificação da presença de eritromicina B em iogurte. Um espectrômetro QqQ foi operado no modo de varredura do íon precursor com monitoramento do fragmento com razão $\mathrm{m} / \mathrm{z}$ de 158 no Q3, que é típico de impurezas comumente presentes na eritromicina A. Foi então encontrado um íon precursor de razão $\mathrm{m} / z$ de 718 no Q1. Aprofundando a investigação, foram realizadas análises nos modos de varredura do íon produto e de monitoramento de reações selecionadas e este composto foi confirmado como a eritromicina $\mathrm{B}$, uma impureza resultante do processo de fermentação para produção da eritromicina. ${ }^{32}$

\section{Quadrupolo - Ion Trap (QIT)}

Constitui-se em um sistema híbrido, composto por dois analisadores de massas diferentes: um quadrupolo e um do tipo armadilha de íons. Este último é formado por três eletrodos, um em forma de anel que fica entre os outros dois, que têm formato hiperbólico e são isolados nas pontas. A diferença de potencial oscilante entre o anel e os eletrodos hiperbólicos gera um campo magnético capaz de confinar ou deixar passar os íons. ${ }^{77,78}$ Este tipo de analisador tem a característica única de conduzir fragmentações em múltiplos estágios $\left(\mathrm{MS}^{\mathrm{n}}\right)$. Quando os íons entram no ion-trap, todas as fragmentações ocorrem no mesmo local, mas em tempos diferentes, apresentando melhor sensibilidade na varredura do que os QqQ, mas com a limitação de não realizar aquisições alternadas entre os modos de varredura do íon produto e de varredura de perda neutra. ${ }^{77,79}$ Além disso, estes instrumentos são menos robustos para análise de matrizes mais complexas e podem apresentar baixa repetibilidade e faixa dinâmica muito estreita para a quantificação ${ }^{80}$ Instrumentos do tipo QIT têm sido usados para caracterizar os padrões de fragmentação de macrolídeos como a azitromicina. Estes experimentos geraram espectros ricos, esclarecedores da estrutura dos macrolídeos em questão, revelando também impurezas em amostras comerciais destes fármacos desconhecidas até então. ${ }^{11,12,56,80,81}$

\section{Triplo-quadrupolo - Ion-Trap linear (QLIT)}

Baseia-se em um tipo de configuração similar ao QqQ, onde o Q3 pode ser operado tanto como um filtro de massas convencional, quanto como uma armadilha de íons com ejeção axial de íons. ${ }^{82,83}$ O QLIT agrupa as vantagens do QqQ e do QIT sem perda de desempenho com relação a seus precursores, podendo ser operado nos mesmos modos que o QqQ, ainda possuindo a habilidade de acúmulo de íons para realizar análises com fragmentações múltiplas para elucidação estrutural. Também possui um recurso de varredura avançada de íons produtos, onde os íons produtos são acumulados no Ion-Trap, possibilitando o aumento de sensibilidade na varredura, o que o torna ideal para análises onde se deseja quantificar e confirmar a identidade de compostos que possuem padrões de fragmentação pobres. ${ }^{17,79}$

\section{Tempo de voo (Time of Flight - ToF) e Quadrupolo - tempo de voo (QToF)}

Em analisadores do tipo ToF, íons com a mesma energia cinética, mas com $m / z$ diferentes são separados em um túnel de voo de 1 a
$2 \mathrm{~m}$ de comprimento sem campo magnético. Instrumentos do tipo ToF são configurados como ToF simples ou em sistemas híbridos em série como o analisador quadrupolo - tempo de voo (QToF). Este último é construído de maneira a direcionar os íons ortogonalmente do quadrupolo ao tempo de voo, através de um acelerador de íons, para análises no modo de espectrometria de massas em série (MS/ MS) com varredura dos íons produtos. ${ }^{84,85} \mathrm{~A}$ grande vantagem destes analisadores está no fato de oferecerem informações espectrais completas com resolução de média a alta, medida de massa exata e excelente sensibilidade no modo de varredura total. Não há dúvida de que os espectrômetros QqQ e QLIT são superiores para a quantificação, mas os dados adquiridos nestes analisadores são limitados à natureza das transições SRM e às $m / z$ nominais dos íons precursores e produtos, desta forma, parte da informação qualitativa para elucidação estrutural e identificação de compostos é perdida. Os analisadores de massas do tipo ToF, ou sistemas híbridos do tipo QToF, permitem a análise de composição elementar, através da medição precisa da razão $\mathrm{m} / \mathrm{z}$ e, consequentemente, a quantificação e confirmação inequívocas dos analitos, bem como a triagem e quantificação de compostos desconhecidos ou produtos de degradação. Sendo assim, analisadores do tipo ToF são ideais para a busca de compostos cuja presença é suspeita nas amostras. Estes espectrômetros de massas têm sido utilizados em métodos de rotina para triagem de multirresíduos de macrolídeos. ${ }^{19,86-89}$

Em um estudo para a determinação de seis macrolídeos em ovos, leite integral e mel, usando-se a técnica UHPLC-QToF obtiveram-se limites de detecção entre 0,1 e $1 \mu \mathrm{g} \mathrm{kg}^{-1}$, adequados para atender os requisitos regulatórios em análises de rotina, e identificou a desmicosina (tilosina B) em mel, baseando-se na medição de massa precisa e usando o recurso de composição elementar. ${ }^{19}$ A tilosina A sofre hidrólise e perde uma molécula de micarose, formando a tilosina $\mathrm{B}$ a $\mathrm{pH} 4$, que é muito próximo ao $\mathrm{pH}$ médio típico do mel (entre $3,4-6,1) .{ }^{15} \mathrm{~A}$ análise por UHPLC-QToF permitiu a determinação da tilosina e a identificação de seu produto de degradação nesta matriz, sem a necessidade de uso de um padrão analítico da tilosina $\mathrm{B}$, o que seria difícil de obter com espectrômetros do tipo QqQ ou QLIT. Este estudo ainda comparou o desempenho do método com relação à linearidade, à precisão e aos limites de detecção por UHPLC-QToF e HPLC-QqQ, e demonstrou que a técnica HPLC-QqQ tem faixa linear mais ampla que a UHPLC-QToF, mesmo com o recurso de melhora de faixa dinâmica habilitado na segunda técnica. A técnica HPLC-QqQ ainda apresentou melhor repetibilidade, devido ao maior número de pontos adquiridos ao longo dos picos cromatográficos.

Estima-se que a detectabilidade de espectrômetros ToF e QToF seja de uma a duas ordens de magnitude inferior aos QqQ no modo SRM. ${ }^{90-92}$ Desta forma, a aplicabilidade da espectrometria de massas ToF ou QToF para quantificação de resíduos de contaminantes em matrizes alimentícias é um desafio, devido às baixas concentrações destas substâncias nestas amostras. A Tabela 1 resume as condições de análise para quantificação de macrolídeos por LC-MS (HPLC-MS ou UHPLC-MS) em estudos recentemente reportados.

\section{VALIDAÇÃO DE MÉTODOS ANALÍTICOS}

Os métodos analíticos para a determinação de contaminantes em alimentos em níveis residuais são a principal ferramenta para assegurar que eles estejam dentro dos Limites Máximos de Resíduos (LMR) legalmente estabelecidos. A realização da validação analítica destes métodos visa certificar que forneçam resultados confiáveis e que garantam a disponibilidade de alimentos seguros. A validação deve ser considerada quando se desenvolve um novo método ou se efetuam adaptações em métodos já validados, quando se pretende avaliar a inclusão de novas técnicas, o uso de diferentes equipamentos, 
Tabela 1. Condições de análise para quantificação de macrolídeos por LC-MS ou UHPLC-MS

\begin{tabular}{|c|c|c|c|c|c|c|c|c|c|c|}
\hline \multirow{2}{*}{ Matriz } & \multirow{2}{*}{ Macrolídeo } & \multicolumn{2}{|c|}{ Preparo de amostra } & \multicolumn{2}{|c|}{ Técnica cromatográfica } & \multicolumn{3}{|c|}{ Espectrometria de massas } & \multirow{2}{*}{$\frac{\text { Limite Analítico }\left(\mu \mathrm{g} \mathrm{kg}^{-1}\right)}{(\mathrm{LD}, \mathrm{LQ}, \mathrm{CC} \alpha \text { ou CC } \beta)}$} & \multirow{2}{*}{ Ref } \\
\hline & & (Extração) & (LE) & $(\mathrm{FE})$ & $(\mathrm{FM})$ & (m/z e/ou transições) & (FI) & $(\mathrm{AM})$ & & \\
\hline \multirow{7}{*}{$\begin{array}{l}\text { Ovos, leite } \\
\text { integral e } \\
\text { mel }\end{array}$} & ESP & \multirow{7}{*}{$\begin{array}{l}\text { Desprot. com } \\
\text { ACN e/ou ex- } \\
\text { tração com tp. } \\
\text { fosfato } 0,1 \mathrm{M} \\
\quad(\mathrm{pH} 8,0)\end{array}$} & \multirow{7}{*}{ HLB } & \multirow{7}{*}{$\begin{array}{c}\text { (HPLC) } \\
\text { AQ S-3, 50 x } \\
2,0 \mathrm{~mm}\end{array}$} & \multirow{7}{*}{$\begin{array}{c}\text { (UHPLC) } \\
\text { acetato de amônio } 10 \mathrm{mM} \\
\text { (HPLC) } \\
\text { ACN e ác. fórmico } 0,1 \%\end{array}$} & $\begin{array}{c}\text { QToF: } 843,5218 \\
\text { QqQ: } 843 \rightarrow 174,142\end{array}$ & \multirow{7}{*}{ ESI } & \multirow{4}{*}{$\begin{array}{l}\text { (UH- } \\
\text { PLC) } \\
\text { QToF }\end{array}$} & $\begin{array}{l}\text { UHPLC-QToF: 0,8 a 1,0 (LD) } \\
\text { HPLC-QqQ: } 0,1 \text { a } 0,2 \text { (LD) }\end{array}$ & \multirow{7}{*}{19} \\
\hline & ERT & & & & & $\begin{array}{c}\text { QToF: } 734,4690 \\
\text { QqQ: } 734 \rightarrow 158,576\end{array}$ & & & $\begin{array}{l}\text { UHPLC-QToF: 0,2 a 0,5 (LD) } \\
\text { HPLC-QqQ: 0,01 (LD) }\end{array}$ & \\
\hline & NEP & & & & & $\begin{array}{c}\text { QToF: } 699,4432 \\
\text { QqQ: } 699 \rightarrow 174,142\end{array}$ & & & $\begin{array}{l}\text { UHPLC-QToF: 1,0 (LD) } \\
\text { HPLC-QqQ: 0,1 a 0,2 (LD) }\end{array}$ & \\
\hline & OLD & & & & & $\begin{array}{c}\text { QToF: } 688,4272 \\
\text { QqQ: } 688 \rightarrow 158,544\end{array}$ & & & $\begin{array}{l}\text { UHPLC-QToF: 0,2 a 0,5 (LD) } \\
\text { HPLC-QqQ: 0,01 (LD) }\end{array}$ & \\
\hline & TLM & & & & & $\begin{array}{c}\text { QToF: } 869,5738 \\
\text { QqQ: } 869 \rightarrow 174,132\end{array}$ & & \multirow[t]{2}{*}{$\begin{array}{c}\text { (HPLC) } \\
\text { QqQ }\end{array}$} & $\begin{array}{l}\text { UHPLC-QToF: 1,0 (LD) } \\
\text { HPLC-QqQ: 0,2 a 0,5 (LD) }\end{array}$ & \\
\hline & TLO A & & & & & $\begin{array}{c}\text { QToF: } 916,5270 \\
\text { QqQ: } 916 \rightarrow 174,145\end{array}$ & & & $\begin{array}{l}\text { UHPLC-QToF: 1,0 (LD) } \\
\text { HPLC-QqQ: 0,2 a 0,5 (LD) }\end{array}$ & \\
\hline & TLO B & & & & & QToF: 772,4483 & & & $\begin{array}{c}\text { UHPLC-QToF: 0,2 (LD) } \\
\text { HPLC-QqQ: 0,01 a 0,02 (LD) }\end{array}$ & \\
\hline \multirow{2}{*}{ Mel } & TLO A & \multirow{2}{*}{$\begin{array}{l}\text { Dissol. em } \\
\text { ACN e água } \\
(3: 7)\end{array}$} & & \multirow{2}{*}{$\begin{array}{l}\text { Luna C8 } 150 \times 2 \\
\mathrm{~mm}, 5 \mu \mathrm{m}\end{array}$} & \multirow{2}{*}{$\begin{array}{l}\text { Ác. heptafluorobutírico } \\
0,04 \%, \text { ACN e acetato de } \\
\text { etila }\end{array}$} & $916 \rightarrow 174,772$ & \multirow[b]{2}{*}{ ESI } & \multirow[b]{2}{*}{ QqQ } & $0,4(\mathrm{LD})$ e 1,5 (LQ) & \multirow[b]{2}{*}{36} \\
\hline & TLO B & & & & & $772 \rightarrow 174,156$ & & & $1,1(\mathrm{LD})$ e 3,7 (LQ) & \\
\hline & ERT & & & & & $734 \rightarrow 158,576$ & & & Leite: 1,0 (LD) e 2,0 (LQ) & \\
\hline Leite & ESP & (MSPD) & & Alltima C18 & Ác. fórmico $10 \mathrm{mM} \mathrm{e}$ & $438 \rightarrow 101,174$ & ESI & ค९ด & $\begin{array}{l}\text { Iogurte: } 5,0(\mathrm{LD}) \text { e } 8,0(\mathrm{LQ}) \\
\text { Leite: } 2,0(\mathrm{LD}) \text { e } 6,0(\mathrm{LQ})\end{array}$ & \\
\hline $\begin{array}{l}\text { bovino e } \\
\text { iogurte }\end{array}$ & TLM & $70^{\circ} \mathrm{C}$ & & $5 \mu \mathrm{m}$ & $\mathrm{MeOH}$ & $870 \rightarrow 174,697$ & LS1 & रपर & $\begin{array}{l}\text { Iogurte: } 0,9(\mathrm{LD}) \text { e } 2,0(\mathrm{LQ}) \\
\text { Leite: } 0,3(\mathrm{LD}) \text { e } 0,9(\mathrm{LQ})\end{array}$ & 35 \\
\hline & TLO & & & & & $916 \rightarrow 174,772$ & & & $\begin{array}{l}\text { Iogurte: } 1,0(\mathrm{LD}) \text { e } 2,0(\mathrm{LQ}) \\
\text { Leite: } 1,0(\mathrm{LD}) \text { e } 2,0(\mathrm{LQ})\end{array}$ & \\
\hline Ovos & TLO & $\begin{array}{l}\text { LLE com tp. } \\
\text { citrato } 0,1 \mathrm{M} \\
(\mathrm{pH} 5) \text { e ACN }\end{array}$ & & $\begin{array}{l}\text { Puresil C18 } 150 \\
\text { x 4,6 mm, } 5 \mu \mathrm{m}\end{array}$ & $\begin{array}{c}\text { Ác. fórmico } 0,5 \% \text {, acetato } \\
\text { de amônio } 1 \mathrm{mM}(\mathrm{pH} 5) \\
\text { e ACN }\end{array}$ & $916 \rightarrow 772,407,754$ & ESI & QIT & $1,0(\mathrm{LQ})$ & 53 \\
\hline & ERT & Dissol. em & & & & $734 \rightarrow 756,158$ & & & $29,7(\mathrm{CC} \alpha)$ e $60,8(\mathrm{CC} \beta)$ & \\
\hline & OLD & $\begin{array}{c}\text { tp. fosfato } \\
0,1 \mathrm{M}(\mathrm{pH} 8,0)\end{array}$ & & & & $688 \rightarrow 158,544$ & & & $27,4(\mathrm{CC} \alpha)$ e $41,0(\mathrm{CC} \beta)$ & \\
\hline & RXT & $\begin{array}{l}\text { seguida de ex- } \\
\text { tração líquida }\end{array}$ & & & Ác nanofluoropentanoico 1 & $837 \rightarrow 158,679$ & & & $27,8(\mathrm{CC} \alpha)$ e $43,1(\mathrm{CC} \beta)$ & \\
\hline Mel & ESP & $\begin{array}{l}\text { com ACN, ác. } \\
\text { tricloroacético }\end{array}$ & & $\begin{array}{l}\text { Zorbax C18 } 50 \\
\text { x } 2,1 \mathrm{~mm}, 1,8 \mu \mathrm{m}^{1}\end{array}$ & $\mathrm{mM}$, ác. fórmico $0,5 \%, \mathrm{ACN}$ & $843 \rightarrow 174,540$ & ESI & QqLIT & $29,4(\mathrm{CC} \alpha)$ e $45,3(\mathrm{CC} \beta)$ & 20 \\
\hline & TLM & $\begin{array}{l}\text { 10\%; ác. nano- } \\
\text { fluoropenta- }\end{array}$ & & & & $869 \rightarrow 174,156$ & & & $31,4(\mathrm{CC} \alpha)$ e $80,9(\mathrm{CC} \beta)$ & \\
\hline & TLO & $\begin{array}{c}\text { noico } 4 \% \text { em } \\
\text { ACN; e água a }\end{array}$ & & & & $916 \rightarrow 174,156$ & & & $27,6(\mathrm{CC} \alpha)$ e $48,0(\mathrm{CC} \beta)$ & \\
\hline & TLO B & $65^{\circ} \mathrm{C}$ & & & & $772 \rightarrow 174,156$ & & & - & \\
\hline & TLO A & & & & & 916 & & & $2,0(\mathrm{LD})$ e $9,0(\mathrm{LQ})$ & \\
\hline Mel & TLO B & $\begin{array}{l}\text { Extraçao com } \\
\text { tp. } \mathrm{Na}_{2} \mathrm{CO}_{3^{-}}^{-}\end{array}$ & Strata-X & Luna $\mathrm{C} 18,150 \mathrm{x}$ & Ác fórmico $0.1 \%$ e ACN & 772 & ESI & 0 & $3,0(\mathrm{LD})$ e $9,0(\mathrm{LQ})$ & 14 \\
\hline & TLO C & $\begin{array}{l}\mathrm{NaHCO}_{3} 0,1 \mathrm{M} \\
(\mathrm{pH} 9)\end{array}$ & & 4,6mm, $5 \mu \mathrm{m}$ & & 902 & & & $2,0(\mathrm{LD})$ e $6,0(\mathrm{LQ})$ & \\
\hline & TLO D & & & & & 918 & & & $2,0(\mathrm{LD})$ e $8,0(\mathrm{LQ})$ & \\
\hline & ERT & DrOI & & & & $734 \rightarrow 158,558,576$ & & & $0,2(\mathrm{LD})$ & \\
\hline & OLD & com ACN e & & YMC ODS-AQ & & $688 \rightarrow 158,544$ & & & $0,1(\mathrm{LD})$ & \\
\hline Ovos & ESP & $\begin{array}{l}\text { extração com } \\
\text { tp. fosfato } 0,1\end{array}$ & HLB & $50 \times 2,0 \mathrm{~mm}$, & Ác. fórmico $0,1 \%$ e ACN & $843 \rightarrow 174,540,318$ & ESI & QqQ & 0,9 (LD) & 18 \\
\hline & TLM & $\mathrm{M}(\mathrm{pH} \mathrm{8)}$ & & & & $869 \rightarrow 174,156$ & & & 0,3 (LD) & \\
\hline & TLO & & & & & $916 \rightarrow 174,145,772$ & & & $0,1(\mathrm{LD})$ & \\
\hline & ERT & & & & & $734 \rightarrow 158,576$ & & & 0,07 (LD) & \\
\hline & OLD & Desprot. & & & & $688 \rightarrow 158,544$ & & & 0,09 (LD) & \\
\hline Leite & ESP & $\begin{array}{l}\text { com } \mathrm{ACN} \text { e } \\
\text { extração com } \\
\text { tp. fosfato } 0,1\end{array}$ & HLB & $\begin{array}{l}\text { YMC ODS-AQ, } \\
50 \times 2 \mathrm{~mm}, 3 \mu \mathrm{m}\end{array}$ & Ác. fórmico $0,1 \%$ e ACN & $\begin{array}{l}843 \rightarrow 174,142 \\
422 \rightarrow 101,142\end{array}$ & ESI & QqQ & 0,08 (LD) & 28 \\
\hline & TLM & $\mathrm{M}(\mathrm{pH} 8)$ & & & & $869 \rightarrow 174,132$ & & & 0,3 (LD) & \\
\hline & TLO & & & & & $916 \rightarrow 174,145$ & & & 0,06 (LD) & \\
\hline & ERT & & & & & $734 \rightarrow 158,576$ & & & $0,22(\mathrm{CC} \alpha)$ e $0,26(\mathrm{CC} \beta)$ & \\
\hline & JOS & Extração com & & Synergi Hydro- & & $828 \rightarrow 147,600$ & & & $0,24(\mathrm{CC} \alpha)$ e $0,26(\mathrm{CC} \beta)$ & \\
\hline Mel & ESP & tp. TRIS $0,1 \mathrm{M}$ & HLB & $\mathrm{RP} 150 \times 2,0$ & $\begin{array}{c}\text { Acetato de amônio } 0,01 \mathrm{M} \\
(\mathrm{pH} 3,5) \text { e } \mathrm{ACN}\end{array}$ & $843 \rightarrow 174,318$ & ESI & QqQ & $1,9(\mathrm{CC} \alpha)$ e $2,1(\mathrm{CC} \beta)$ & 23 \\
\hline & TLM & & & & & $870 \rightarrow 174,696$ & & & $0,23(\mathrm{CC} \alpha)$ e $0,25(\mathrm{CC} \beta)$ & \\
\hline & TLO & & & & & $916 \rightarrow 174,772$ & & & $0,22(\mathrm{CC} \alpha)$ e $0,24(\mathrm{CC} \beta)$ & \\
\hline
\end{tabular}


Tabela 1. continuação

\begin{tabular}{|c|c|c|c|c|c|c|c|c|c|c|}
\hline \multirow{2}{*}{ Matriz } & \multirow{2}{*}{ Macrolídeo } & \multicolumn{2}{|c|}{ Preparo de amostra } & \multicolumn{2}{|c|}{ Técnica cromatográfica } & \multicolumn{3}{|c|}{ Espectrometria de massas } & \multirow{2}{*}{$\begin{array}{c}\text { Limite Analítico }\left(\mu \mathrm{g} \mathrm{kg}^{-1}\right) \\
(\mathrm{LD}, \mathrm{LQ}, \mathrm{CC} \alpha \text { ou CC } \beta)\end{array}$} & \multirow{2}{*}{ Ref } \\
\hline & & (Extração) & (LE) & (FE) & $(\mathrm{FM})$ & ( $\mathrm{m} / \mathrm{z}$ e/ou transições) & (FI) & $(\mathrm{AM})$ & & \\
\hline Truta & ERT & $\begin{array}{l}\text { Desprot. com } \\
\text { ACN }\end{array}$ & $\begin{array}{l}\text { Remoção de } \\
\text { lipídeos com } \\
\text { hexano }\end{array}$ & $\begin{array}{c}\text { Symmetry C18 } \\
150 \times 4,6 \mathrm{~mm} \\
3,5 \mu \mathrm{m}\end{array}$ & $\begin{array}{c}\text { Acetato de amônio } 1 \mathrm{mM} \\
\text { com } 0,1 \% \text { de ác. acético; } \\
\text { ACN }\end{array}$ & $734 \rightarrow 576,558,716$ & ESI & QqQ & $220(\mathrm{CC} \alpha)$ e $238(\mathrm{CC} \beta)$ & 25 \\
\hline \multirow{2}{*}{ Ovos } & ERT & \multirow{2}{*}{$\begin{array}{l}\text { Desprot. com } \\
\text { ACN }\end{array}$} & \multirow{2}{*}{$\begin{array}{l}\text { Silica SPE } \\
\text { Supelclean } \\
\text { LC-SI }\end{array}$} & \multirow{2}{*}{$\begin{array}{c}\text { YMC phenyl } 50 \\
\mathrm{x} 4 \mathrm{~mm}, 3 \mu \mathrm{m}\end{array}$} & \multirow{2}{*}{ Ác. fórmico 0,1\% e ACN } & $734 \rightarrow 576,522,558$ & \multirow[b]{2}{*}{ ESI } & \multirow[b]{2}{*}{ QIT } & $1,0(\mathrm{LD})$ & \multirow[b]{2}{*}{27} \\
\hline & TLO & & & & & $916 \rightarrow 772,407,598$ & & & $1,0(\mathrm{LD})$ & \\
\hline Mel & TLO & $\begin{array}{l}\text { Dissol. em } \\
\text { tp. } \mathrm{Na}_{2} \mathrm{CO}_{3} \\
-\mathrm{NaHCO}_{3} \\
(\mathrm{pH} \mathrm{9)}\end{array}$ & $\begin{array}{l}\text { Bond Elut } \\
\text { C18 }\end{array}$ & $\begin{array}{l}\text { Zorbax C8 } 150 \mathrm{x} \\
2,1 \mathrm{~mm}, 5 \mu \mathrm{m}\end{array}$ & $\begin{array}{c}\text { Ác. trifluoroacético, } \mathrm{MeOH} \\
\text { e ACN }\end{array}$ & 916,174 & APCI & $\mathrm{Q}$ & $0,01(\mathrm{LD})$ & 24 \\
\hline $\begin{array}{l}\text { Músculo } \\
\text { e pele de } \\
\text { salmão }\end{array}$ & ERT & $\begin{array}{l}\text { Extração com } \\
\text { tp. formato } 10^{1} \\
\mathrm{mM}\end{array}$ & $\begin{array}{l}\text { HLB e } \\
\text { partição com } \\
\text { cloreto de } \\
\text { metileno }\end{array}$ & $\begin{array}{l}\text { Prodigy ODS(3) } \\
250 \times 2 \text { mm }\end{array}$ & $\begin{array}{c}\text { Formato de amônio } 3 \mathrm{mM} \\
\text { e ACN }\end{array}$ & $734,576,558,158$ & ESI & Q & & 93 \\
\hline \multirow{3}{*}{ Ovos } & ERT & \multirow{3}{*}{$\begin{array}{l}\text { Desprot. com } \\
\text { ACN }\end{array}$} & \multirow{3}{*}{ - } & \multirow{3}{*}{$\begin{array}{c}\text { ACE C } 18 \\
50 \times 2,1 \mathrm{~mm}, \\
3 \mu \mathrm{m}\end{array}$} & \multirow{3}{*}{ Ác. fórmico, $\mathrm{MeOH}$ e ACN } & $734,576,158,116$ & \multirow{3}{*}{ ESI } & \multirow{3}{*}{ QqQ } & $\begin{array}{c}0,09(\mathrm{LD}) ; 0,29(\mathrm{LQ}) ; \\
174,9(\mathrm{CC} \alpha) \text { e } 207,5(\mathrm{CC} \beta)\end{array}$ & \\
\hline & TLO & & & & & $916,772,174,116$ & & & $\begin{array}{c}0,16(\mathrm{LD}) ; 0,53 \text { (LQ); } \\
229,7 \text { (CC } \alpha) \text { e 262,7 (CC } \beta)\end{array}$ & 38 \\
\hline & CLT & & & & & $748,590,158,116$ & & & $\begin{array}{c}0,15 \text { (LD); 0,50 (LQ); } \\
0,87 \text { (CC } \alpha \text { ) e 1,74 (CC } \beta)\end{array}$ & \\
\hline \multirow{2}{*}{$\begin{array}{c}\text { Peixe } \\
\text { (dourada, } \\
\text { Sparus } \\
\text { aurata) }\end{array}$} & & \multirow{2}{*}{\multicolumn{2}{|c|}{ QuEChERS }} & \multirow{2}{*}{$\begin{array}{c}\text { Acquity UPLC } \\
\text { BEH C18 } \\
100 \times 2,1 \mathrm{~mm}, \\
1,7 \mu \mathrm{m}\end{array}$} & \multirow{2}{*}{ Ác. fórmico e ACN } & $717 \rightarrow 158,116$ & \multirow{2}{*}{ ESI } & & $\begin{array}{c}7,5(\mathrm{LD}) ; 25,0(\mathrm{LQ}) ; \\
210,7(\mathrm{CC} \alpha) \text { e } 221,3(\mathrm{CC} \beta)\end{array}$ & \\
\hline & JOS & & & & & $829 \rightarrow 174,109$ & & QqQ & $\begin{array}{c}\text { 7,5 (LD); 25,0 (LQ); } \\
215,3 \text { (CC } \alpha) \text { e 230,7 (CC } \beta)\end{array}$ & 94 \\
\hline & TLM & & & & & $870 \rightarrow 696,174$ & & & $\begin{array}{c}\text { 1,0 (LD); 3,3 (LQ); } \\
0,5(\mathrm{CC} \alpha) \text { e } 1,7 \text { (CC } \beta)\end{array}$ & \\
\hline $\begin{array}{l}\text { Baby } \\
\text { Foods (à } \\
\text { base de }\end{array}$ & & QuECh & hERS & $\begin{array}{l}\text { Acquity UPLC } \\
\text { BEH C18 }\end{array}$ & Ác fórmico e $\mathrm{MeOH}$ & $917 \rightarrow 174,101$ & ESI $>$ & & $\begin{array}{c}5,0(\mathrm{LD}) ; 15,0(\mathrm{LQ}) ; \\
16,2(\mathrm{CC} \alpha) \text { e } 22,4(\mathrm{CC} \beta)\end{array}$ & \\
\hline $\begin{array}{l}\text { carne e de } \\
\text { leite em } \\
\text { pó) }\end{array}$ & ERT & & & $\begin{array}{c}100 \times 2,1 \mathrm{~mm} \\
1,7 \mu \mathrm{m}\end{array}$ & Ac. Formico e MieOH & $717 \rightarrow 158,116$ & ESI & QqQ & $\begin{array}{c}0,1(\mathrm{LD}) ; 0,3(\mathrm{LQ}) \\
2,6(\mathrm{CC} \alpha) \text { e } 5,2(\mathrm{CC} \beta)\end{array}$ & 95 \\
\hline & JOS & & & & & $829 \rightarrow 174,109$ & & & $\begin{array}{c}0,2(\mathrm{LD}) ; 0,7(\mathrm{LQ}) \\
1,2(\mathrm{CC} \alpha) \text { e } 2,4(\mathrm{CC} \beta)\end{array}$ & \\
\hline & ERT & & & & & $717 \rightarrow 158,116$ & & & $\begin{array}{c}3,2(\mathrm{LD}) ; 10,0(\mathrm{LQ}) ; \\
207,8(\mathrm{CC} \alpha) \text { e } 215,6(\mathrm{CC} \beta)\end{array}$ & \\
\hline Carne de & & $\mathrm{OuECh}$ & hERS & $\begin{array}{l}\text { Acquity UPLC } \\
\text { BEH C18 }\end{array}$ & Ác fórmico e ACN & $829 \rightarrow 174,109$ & ESI & $\mathrm{OgO}$ & $\begin{array}{c}\text { 3,2 (LD); 10,0 (LQ); } \\
19,3 \text { (CC } \alpha \text { ) e 28,7 (CC } \beta)\end{array}$ & 96 \\
\hline frango & TLM & & & $\begin{array}{c}100 \times 2,1 \mathrm{~mm} \\
1,7 \mu \mathrm{m}\end{array}$ & & $870 \rightarrow 696,174$ & & रपर & $\begin{array}{c}\text { 6,4 (LD); } 20,0 \text { (LQ); } \\
111,5(\mathrm{CC} \alpha) \text { e } 148,1 \text { (CC } \beta)\end{array}$ & 30 \\
\hline & TLO & & & & & $917 \rightarrow 174,101$ & & & $\begin{array}{c}16,0(\mathrm{LD}) ; 30,0(\mathrm{LQ}) ; \\
108,2(\mathrm{CC} \alpha) \text { e } 116,5(\mathrm{CC} \beta)\end{array}$ & \\
\hline & TLM & & & & & $435 \rightarrow 339,125$ & & & 0,28 a $0,36(\mathrm{LD})$ e $5,0(\mathrm{LQ})$ & \\
\hline & ESP & & & & & $425 \rightarrow 366,335,173$ & & & 0,31 a $0,41(\mathrm{LD})$ e $5,0(\mathrm{LQ})$ & \\
\hline & ERT A & & & & & $734 \rightarrow 679,558,157$ & & & 0,21 a $0,33(\mathrm{LD})$ e $5,0(\mathrm{LQ})$ & \\
\hline & $\begin{array}{l}\text { Etilsuccinato } \\
\text { - ERT }\end{array}$ & & & & & $734 \rightarrow 558,576,157$ & & & 0,29 a $0,61(\mathrm{LD})$ e $5,0(\mathrm{LQ})$ & \\
\hline & AZT & & & & & $749 \rightarrow 590,157,82$ & & & 0,27 a $0,31(\mathrm{LD})$ e $5,0(\mathrm{LQ})$ & \\
\hline & KTS & & & & & $772 \rightarrow 558,174,109$ & & & 0,20 a $0,31(\mathrm{LD})$ e $5,0(\mathrm{LQ})$ & \\
\hline $\begin{array}{l}\text { Carne, rim } \\
\text { e fígado de }\end{array}$ & CLT & PLE com AC & $\mathrm{CN} / \mathrm{MeOH}$ & Thermo Hypersil & Tp. formato (formato de & $748 \rightarrow 589,157$ & ESI & 000 & 0,27 a $0,28(\mathrm{LD})$ e $5,0(\mathrm{LQ})$ & 39 \\
\hline $\begin{array}{l}\text { suinos e } \\
\text { bovinos }\end{array}$ & TLD & $(1: 1, \mathrm{v}$ & & $2.1 \mathrm{~mm}, 5 \mu \mathrm{m}$ & fómico) e $\mathrm{MeOH}$ & $772 \rightarrow 585,158,116$ & & & 0,25 a $0,50(\mathrm{LD})$ e $5,0(\mathrm{LQ})$ & \\
\hline & MDC & & & & & $814 \rightarrow 173,108$ & & & 0,22 a $0,29(\mathrm{LD})$ e $5,0(\mathrm{LQ})$ & \\
\hline & JOS & & & & & $828 \rightarrow 185,174,108$ & & & 0,31 a $0,56(\mathrm{LD})$ e $5,0(\mathrm{LQ})$ & \\
\hline & TLO & & & & & $916 \rightarrow 173,155,100$ & & & 0,23 a $0,32(\mathrm{LD})$ e $5,0(\mathrm{LQ})$ & \\
\hline & Acetil - ESP II & & & & & $927 \rightarrow 173,108$ & & & & \\
\hline & Acetil - ESP III & & & & & $941 \rightarrow 173,109$ & & & 0,31 a $0,45(\mathrm{LD})$ e 10,0 (LQ) & \\
\hline & Diacetil - ESP II & & & & & $969 \rightarrow 581,173,108$ & & & & \\
\hline
\end{tabular}


Tabela 1. continuação

\begin{tabular}{|c|c|c|c|c|c|c|c|c|c|c|}
\hline \multirow{2}{*}{ Matriz } & \multirow{2}{*}{ Macrolídeo } & \multicolumn{2}{|c|}{ Preparo de amostra } & \multicolumn{2}{|c|}{ Técnica cromatográfica } & \multicolumn{3}{|c|}{ Espectrometria de massas } & \multirow{2}{*}{$\begin{array}{l}\text { Limite Analítico }\left(\mu \mathrm{g} \mathrm{kg}^{-1}\right) \\
(\mathrm{LD}, \mathrm{LQ}, \mathrm{CC} \alpha \text { ou CC } \beta)\end{array}$} & \multirow{2}{*}{ Ref } \\
\hline & & (Extração) & (LE) & (FE) & $(\mathrm{FM})$ & (m/z e/ou transições) & (FI) & (AM) & & \\
\hline \multirow{3}{*}{ Ovos } & ERT A & \multirow{3}{*}{ Desprot. com ACN } & \multirow{3}{*}{-} & \multirow{3}{*}{$\begin{array}{c}\text { Alltech } \mathrm{C}_{18} \\
250 \times 4,6 \mathrm{~mm}, \\
5 \mu \mathrm{m}\end{array}$} & \multirow{3}{*}{ Ác. fórmico e acetonitrila } & $734 \rightarrow 576,158$ & \multirow{3}{*}{ ESI } & \multirow{3}{*}{ QqQ } & $\begin{array}{c}0,2(\mathrm{LD}) ; 0,5(\mathrm{LQ}) ; \\
170(\mathrm{CC} \alpha) \text { e } 220(\mathrm{CC} \beta)\end{array}$ & \\
\hline & TLO & & & & & $916 \rightarrow 772,174$ & & & $\begin{array}{c}0,2(\mathrm{LD}) ; 0,3(\mathrm{LQ}) \\
230(\mathrm{CC} \alpha) \text { e } 290(\mathrm{CC} \beta)\end{array}$ & 97 \\
\hline & TLM & & & & & $435 \rightarrow 695,174$ & & & $\begin{array}{c}0,2(\mathrm{LD}) ; 0,4 \text { (LQ); } \\
5,5(\mathrm{CC} \alpha) \text { e 7,4 (CC } \beta)\end{array}$ & \\
\hline \multirow{5}{*}{$\begin{array}{l}\text { Leite e } \\
\text { carne } \\
\text { bovina }\end{array}$} & TLM & \multirow{5}{*}{\multicolumn{2}{|c|}{$\begin{array}{l}\text { PLE com ACN; } \\
\text { e éter de petróleo } \\
\text { para extrair a } \\
\text { gordura }\end{array}$}} & \multirow{5}{*}{$\begin{array}{c}\text { Discovery HS } \\
\text { C } 18 \\
150 \times 2,1 \mathrm{~mm} \\
3 \mu \mathrm{m}\end{array}$} & \multirow{4}{*}{ Ác. fórmico e ACN } & $869 \rightarrow 696,174 ; 156$ & \multirow{5}{*}{ ESI } & \multirow{5}{*}{ QqQ } & $\begin{array}{l}\text { LEITE: } 5 \text { (LD); } 15 \text { (LQ); } \\
56 \text { (CC } \alpha \text { ) e } 63 \text { (CC } \beta) \\
\text { CARNE: } 10 \text { (LD); } 30 \text { (LQ); } \\
66 \text { (CC } \alpha \text { ) e } 81(C C \beta)\end{array}$ & \multirow{5}{*}{40} \\
\hline & TLO & & & & & $916 \rightarrow 772,174 ; 145$ & & & $\begin{array}{l}\text { LEITE: } 3 \text { (LD); } 10 \text { (LQ); } \\
55 \text { (CC } \alpha \text { ) e } 59 \text { (CC } \beta) \\
\text { CARNE: } 5 \text { (LD); } 10(\mathrm{LQ}) \text {; } \\
112(\mathrm{CC} \alpha) \text { e } 124(\mathrm{CC} \beta)\end{array}$ & \\
\hline & ESP & & & & & $843 \rightarrow 540,318 ; 174$ & & & $\begin{array}{l}\text { LEITE: } 5 \text { (LD); } 15 \text { (LQ); } \\
205 \text { (CC } \alpha \text { ) e } 210 \text { (CC } \beta) \\
\text { CARNE: } 10 \text { (LD); } 20 \text { (LQ); } \\
207 \text { (CC } \alpha \text { ) e } 214(C C \beta)\end{array}$ & \\
\hline & ERT & & & & & $734 \rightarrow 576,558 ; 158$ & & & $\begin{array}{l}\text { LEITE: } 10 \text { (LD); } 15 \text { (LQ); } \\
46 \text { (CC } \alpha \text { ) e } 52 \text { (CC } \beta) \\
\text { CARNE: } 10 \text { (LD); } 25 \text { (LQ); } \\
218 \text { (CC } \alpha \text { ) e } 237 \text { (CC } \beta)\end{array}$ & \\
\hline & TUL & & - & & & $805 \rightarrow 407,158$ & & & $\begin{array}{c}\text { LEITE: } 10 \text { (LD); } 20 \text { (LQ); } \\
0,26 \text { (CC } \alpha \text { ) e } 0,8 \text { (CC } \beta) \\
\text { CARNE: } 5 \text { (LD); } 15 \text { (LQ); } \\
0,25 \text { (CC } \alpha \text { ) e } 1,2(\mathrm{CC} \beta)\end{array}$ & \\
\hline
\end{tabular}

LE: limpeza do extrato; FE: fase estacionária; FM: fase móvel; FI: fonte de ionização; AM: analisador de massas; LD: limite de detecção; LQ: limite de quantificação; CC $\alpha$ : limite de decisão; CC $\beta$ : capacidade de detecção; LLE: extração líquido-líquido; PLE: extração líquida pressurizada; MSPD: dispersão da matriz em fase sólida; ACN: acetonitrila; MeOH: metanol; ESP: espiramicina; ERT: eritromicina; NEP: neoespiramicina; OLD: oleandomicina; TLM: tilmicosina; TLO: tilosina; RXT: roxitromicina; JOS: josamicina; CLT: claritromicina; AZT: azitromicina; KTS: kitasamicina; TLD: troleandomicina; MDC: medecamicina; TUL: tulatromicina

ou, ainda, a extensão do método para a inclusão de novas matrizes. ${ }^{98}$

A IUPAC preconiza que, no que diz respeito à análise de alimentos, os requerimentos para os métodos analíticos envolvam estudos de desempenho a partir de ensaios interlaboratoriais (ensaio de proficiência, estudo colaborativo ou triagem colaborativa), preenchendo os requisitos para comporem o que se classifica como procedimento de validação completa do método analítico (full validation). No entanto, quando se pretende garantir a viabilidade do método antes de se proceder à validação completa, ou para a publicação de artigos científicos, a validação completa de um método analítico não é necessária. Em tais circunstâncias considera-se apropriada a validação do método em um único laboratório (single-laboratory validation ou in-house validation)..$^{98,99}$

No Brasil, os procedimentos adotados para a validação de métodos analíticos baseiam-se em guias disponibilizados por órgãos como a Agência Nacional de Vigilância Sanitária (ANVISA), ${ }^{100} \mathrm{o}$ Ministério da Saúde, o Instituto Nacional de Metrologia e Qualidade Industrial (INMETRO) ${ }^{101}$ e o Ministério da Agricultura, Pecuária e Abastecimento (MAPA). ${ }^{102} \mathrm{~A}$ validação pode também ser baseada em guias internacionais como a Organização Internacional de Normatização (International Organization for Standardization ISO), ${ }^{103}$ a Conferência Internacional em Harmonização (International Conference on Harmonization - ICH), ${ }^{104} \mathrm{ou}$, ainda, as Diretivas da Comunidade Europeia ${ }^{105}$ e guias disponibilizados pela agência dos Estados Unidos para Administração de Drogas e Alimentos (United States - Food and Drug Administration - FDA)..$^{106,107}$

Os parâmetros de validação para métodos analíticos instrumentais baseados na separação cromatográfica por HPLC incluem seletividade, linearidade e faixa de aplicação, exatidão, precisão (repetibilidade, precisão intermediária e reprodutibilidade), limite de detecção (LD), limite de quantificação (LQ) e robustez. Alguns guias, como do MAPA ${ }^{102}$ e da Comunidade Europeia, ${ }^{105}$ incluem a avaliação do limite de decisão $(\mathrm{CC} \alpha)$ e a capacidade de detecção (CC $\beta)$. Todos esses parâmetros são detalhadamente explicados nos diversos guias de validação e são constantemente revisados e discutidos..$^{98,108}$ Para o enfoque proposto nesta revisão, discutiremos os principais aspectos de validação analítica relacionados a métodos estabelecidos para a determinação de contaminantes químicos em alimentos, os quais envolvem o uso da MS como técnica analítica.

$\mathrm{Na}$ validação de métodos analíticos para a determinação de contaminantes tóxicos em alimentos, os LMR específicos de cada analito devem ser considerados ao se construir a curva de calibração, de maneira a assegurar que estas concentrações estejam incluídas na faixa dinâmica de trabalho. A repetibilidade, a exatidão e os limites de detecção e quantificação também devem atender a critérios que garantam que o método seja capaz de detectar e quantificar os analitos em questão inequivocamente em faixas de concentrações próximas aos LMR e que os incluam. ${ }^{98}$

A seletividade é caracterizada pela capacidade de produzir respostas distintas entre os vários analitos e outras substâncias presentes na amostra, garantindo que o sinal analítico seja exclusivamente do composto em estudo. ${ }^{101,108}$ No caso da detecção por espectrometria de massas, torna-se necessário também avaliar o efeito matriz..$^{99,101,108}$

A União Europeia criou um sistema de pontuação em MS para considerar a identificação inequívoca de contaminantes orgânicos em alimentos, conforme a Tabela 2. ${ }^{105}$

Desta forma, como os espectrômetros de massas do tipo QqQ podem fornecer informações sobre fragmentos dos analitos, eles cumprem os requisitos da Comunidade Europeia no que diz respeito à capacidade de quantificação e confirmação de identidade. Mais especificamente, no caso do uso deste tipo de espectrômetro, o monitoramento do íon precursor mais dois íons produtos atende aos requisitos da Comunidade Europeia no que diz respeito à identificação de substâncias não banidas, como é o caso dos macrolídeos. 
Tabela 2. Relação entre os fragmentos mássicos e os pontos de identificação obtidos segundo a Comissão Europeia ${ }^{105}$

\begin{tabular}{lc}
\hline Técnica de espectrometria de massas & $\begin{array}{c}\text { Pontos de identificação } \\
\text { obtidos por íon }\end{array}$ \\
\hline Espectrometria de massas de baixa resolução (LR) & 1,0 \\
LR-MS $^{\mathrm{n}}$ - íon precursor & 1,0 \\
LR-MS $^{\mathrm{n}}$ - íon produto & 1,5 \\
Espectrometria de massas de alta resolução (HR) & 2,0 \\
HR-MS $^{\mathrm{n}}$ - íon precursor & 2,0 \\
HR-MS $^{\mathrm{n}}$ - íon produto & 2,5 \\
\hline
\end{tabular}

Obs.: Cada íon pode ser contabilizado uma única vez; substâncias diferentes podem ser consideradas para aumentar o número de pontos se derivarem de diferentes mecanismos de reação; são considerados como íon produto tanto os de segunda, quanto os de terceira geração; a espectrometria de massas pode ser considerada de alta resolução se for tipicamente superior a 10000 para todo o intervalo mássico a $10 \%$ do vale. LR - Low Resolution. HR - High Resolution

Ainda segundo estes critérios, pelos menos dois íons (um precursor e um produto) devem ser monitorados para se atingir a pontuação de identificação mínima de três em espectrômetros de massas da alta resolução.

Cabe avaliar que estas definições da Comunidade Europeia não levam em consideração a exatidão da razão $\mathrm{m} / z$ p para a confirmação de um contaminante químico, desconsiderando instrumentos que têm exatidão de massas de até 5 ppm, que fornecem especificidade suficiente para a confirmação dos compostos alvo e permitem a atribuição de possíveis composições elementares, mas que não fornecem resolução superior a $10.000 .{ }^{17}$ Assim, novos critérios foram propostos para a atribuição da pontuação de identificação que usam o erro absoluto ou relativo de massas ao invés da resolução de massa, sendo que o segundo ainda traria a vantagem de que o critério de pontuação seria válido dentro de uma faixa de massas, independentemente dos valores de $m / z .{ }^{19}$ Segundo estes critérios, o monitoramento de dois íons, com erros de massas no intervalo de 2 a 10 ppm, seria suficiente para se atingir a pontuação mínima de identificação. Por exemplo, usando a dissociação por colisão induzida, instrumentos do tipo QToF poderiam adquirir espectros ricos em fragmentos e, consequentemente, mais pontos seriam atribuídos para a confirmação do composto.

O FDA dos EUA exige que a abundância relativa entre dois íons produtos monitorados coincida com a do padrão analítico da substância em $\pm 10 \%$ de tolerância, sendo que quando são monitorados três íons fragmentos essa tolerância sobe para $\pm 20 \%$. ${ }^{107}$ É importante ressaltar que as abundâncias relativas entre os íons de macrolídeos obtidos em espectrometria de massas permanecem consistentes dentro de um mesmo dia de análise, mas podem variar entre análises realizadas em dias diferentes. ${ }^{21}$ Desta forma, as intensidades relativas dos íons de macrolídeos devem ser comparadas com seus padrões analíticos sob as mesmas condições analíticas, ou seja, na mesma batelada de análises. ${ }^{28,35}$ A consistência nos tempos de retenção cromatográfica e também das abundâncias relativas entre os íons no espectro de massas são essenciais para a confirmação da presença dos macrolídeos nas amostras.

\section{PRESENÇA DE MACROLÍDEOS EM ALIMENTOS E ASPECTOS DE REGULAMENTAÇÃO}

A presença de macrolídeos na cadeia alimentícia como consequência de seu uso na medicina veterinária tem preocupado o meio acadêmico e as autoridades reguladoras e fiscalizadoras, devido a seu impacto em questões de saúde pública e de comércio internacional. A Organização Mundial da Saúde (OMS) trata dos problemas relacionados à presença de contaminantes em alimentos em relatórios emitidos pela Organização das Nações Unidas para a Agricultura e Alimentação (Food and Agriculture and Organization of the United Nations - FAO). ${ }^{109}$

Para garantir a segurança na cadeia de suprimento de alimentos aos consumidores e viabilizar o comércio internacional de alimentos, órgãos internacionais (Codex Alimentarius) ${ }^{110}$ e blocos econômicos regionais (União Europeia e MERCOSUL) - através de órgãos e comitês especializados em segurança alimentar, ${ }^{13,111}$ assim como agências nacionais de regulamentação (FDA, MAPA e Ministério da Saúde do Brasil, Ministério do Trabalho e do Bem-Estar do Japão) $)^{110-114}$ estabeleceram LMR de antimicrobianos nos alimentos, incluindo os macrolídeos, com bases em dados toxicológicos, como os valores aceitáveis de ingestão diária, e na capacidade de detecção e quantificação dos métodos analíticos disponíveis. A Tabela 3 indica os LMR estabelecidos pela Comunidade Europeia, ${ }^{13}$ pelo Codex Alimentarius, ${ }^{109}$ pelo Ministério da Agricultura do Brasil, ${ }^{112}$ pelo Ministério da Saúde, do Trabalho e do Bem Estar do Japão ${ }^{114}$ e pelo FDA dos EUA ${ }^{110}$ para alguns macrolídeos.

No Brasil, o Ministério da Saúde, através da ANVISA, é o órgão que coordena e controla as atividades de inspeção, registro e controle de risco, bem como estabelece normas e padrões relativos à segurança alimentar. Em 2003 a ANVISA oficializou o Programa Nacional de Análise de Resíduos de Medicamentos Veterinários em Alimentos Expostos ao Consumo - PAMVet, com o objetivo de operacionalizar o controle e a fiscalização dos resíduos de medicamentos veterinários em diversas matrizes alimentares como leite bovino, carne de frango, carne bovina, carne suína, pescado, ovo de galinha e mel de abelha. Porém, até o momento, apenas análises em amostras de leite vêm sendo realizadas. O leite vem sendo monitorado quanto à presença de diversos fármacos, e a eritromicina é a única substância representante do grupo dos macrolídeos monitorada por este programa. ${ }^{113}$

O MAPA compartilha as atividades de vigilância sanitária com a ANVISA e em 1995 instituiu o Plano Nacional de Controle de Resíduos Biológicos em Produtos de Origem Animal (PNCRB), o qual prevê a adoção de programas setoriais de controle de remanescentes residuais em carne, leite, mel, ovos e pescado, em decorrência do uso de agrotóxicos e medicamentos veterinários, ou por acidentes envolvendo contaminantes ambientais. ${ }^{115}$ O PNCRB de 2010 prevê a determinação de resíduos de representantes das classes dos macrolídeos em algumas matrizes como carne de suínos, de equinos, de bovinos e de aves e mel. ${ }^{112}$

Lamentavelmente, a fiscalização e a comunicação de risco com relação à presença de contaminantes em alimentos no Brasil têm ocorrido principalmente como consequência da não adequação às exigências do mercado externo, deixando em segundo plano a proteção da saúde da população propriamente dita. ${ }^{116}$ Desta forma, no caso dos limites máximos de resíduos não estarem estabelecidos pelo MAPA, utilizam-se os internalizados no Mercado Comum do Sul (MERCOSUL), os recomendados pelo Codex Alimentarius, os constantes nas Diretivas da Comissão da União Europeia e/ou os utilizados pelo FDA.

É importante ressaltar que a josamicina não está incluída na lista de medicamentos veterinários permitidos para uso em animais para a produção de alimentos pelo MAPA, pelo FDA e pelo Codex Alimentarius. ${ }^{110,112,117} \mathrm{O}$ MAPA e o FDA também não incluem a espiramicina dentre os antimicrobianos permitidos na pecuária. ${ }^{12,117}$ Dentre os LMR estabelecidos pelo MERCOSUL, o único antimicrobiano da classe dos macrolídeos citado é a eritromicina. ${ }^{11}$ A União Europeia baniu o uso de espiramicina e tilosina como aditivos à ração (como promotores de crescimento) devido à crescente preocupação com a transferência de resistência entre diferentes bactérias e entre animais e humanos. ${ }^{59}$ 
Tabela 3. Limites máximos de resíduos $\left(\mathrm{em} \mu \mathrm{g} \mathrm{kg}^{-1}\right)$ de alguns macrolídeos em várias matrizes alimentícias

\begin{tabular}{|c|c|c|c|c|c|c|c|c|c|}
\hline Macrolídeo & $\begin{array}{l}\text { Resíduo } \\
\text { Marcador* }\end{array}$ & Espécie & Matriz & $\begin{array}{l}\text { LMR } \\
(\mathrm{UE})^{13}\end{array}$ & $\begin{array}{l}\text { LMR } \\
(\mathrm{CA})^{110}\end{array}$ & $\begin{array}{l}\text { Limite de } \\
\text { referência } \\
(\text { MAPA) })^{112}\end{array}$ & $\begin{array}{c}\text { LMR } \\
\left(_{(M E R C O S U L}\right)^{111}\end{array}$ & $\begin{array}{c}\text { LMR } \\
(\text { FDA })^{110}\end{array}$ & $\begin{array}{c}\text { LMR } \\
\text { (Japão) })^{114}\end{array}$ \\
\hline \multirow{6}{*}{ ERT } & \multirow{6}{*}{ ERT A } & Todas as produtoras de alimentos & & 200 & & & & & \\
\hline & & Gado, suínos, frangos & Músculo & & & 200 & 400 & 100 & 50 \\
\hline & & Frango & & & 100 & & & 125 & \\
\hline & & Abelha & Mel & & & 10 & & & \\
\hline & & Gado & Leite & 40 & & & 40 & & 40 \\
\hline & & Galinha & Ovos & 150 & 50 & & 200 & 25 & 90 \\
\hline \multirow[t]{2}{*}{ ESP } & \multirow[t]{2}{*}{ ESP e NEP } & Gado, frango & Músculo & 200 & 200 & & & & \\
\hline & & Suínos & & 300 & 200 & & & & \\
\hline \multirow{5}{*}{ TLM } & \multirow{5}{*}{ TLM } & $\begin{array}{c}\text { Todas as produtoras de alimentos - } \\
\text { exceto aves }\end{array}$ & & 50 & & & & & \\
\hline & & Frango & & 75 & & 250 & & & 70 \\
\hline & & Suínos & Músculo & & 100 & 1000 & & 100 & 100 \\
\hline & & Gado & & & 100 & 300 & & 100 & 100 \\
\hline & & Caprinos & & & 100 & & & 100 & 100 \\
\hline \multirow{8}{*}{ TLO } & \multirow{8}{*}{ TLO A } & Todas as produtoras de alimentos & & 100 & & & & & \\
\hline & & Suíno & & & 100 & 100 & & 200 & 50 \\
\hline & & Gado & Músculo & & 100 & 100 & & 200 & 50 \\
\hline & & Aves & & & & 100 & & & \\
\hline & & Frango & & & 100 & & & 200 & 50 \\
\hline & & Galinha & Ovos & 200 & 300 & & & 200 & 200 \\
\hline & & Gado & Leite & 50 & 100 & & & 50 & 50 \\
\hline & & Abelha & Mel & & & 10 & & & \\
\hline
\end{tabular}

JOS Aves, suínos $\quad$ Músculo 200

UE: União Europeia; CA: Codex Alimentarius; ESP: espiramicina; ERT: eritromicina; NEP: neoespiramicina; TLM: tilmicosina; TLO: tilosina; JOS: josamicina. * Resíduo marcador: resíduo cuja concentração decresce em uma correlação conhecida com a concentração de resíduos totais nos tecidos animais, no ovo, no leite ou no mel.

\section{CONCLUSÕES}

Os macrolídeos são antimicrobianos comumente usados na medicina veterinária que estão sob a regulamentação das agências nacionais e internacionais de segurança alimentar e podem eventualmente ser encontrados nos alimentos.

Dentre as técnicas para tratamento de amostras alimentícias para análise de macrolídeos, a extração em fase sólida com cartuchos HLB ${ }^{\circledR}$ tem se destacado, já que a complexidade deste tipo de matriz leva à necessidade de limpeza e concentração do extrato. Ainda assim, o uso de outras fases estacionárias e técnicas como a partição e a extração líquido-líquido têm sido reportadas. A seleção do método de extração depende da natureza da matriz e do tipo de estudo a ser realizado.

A espectrometria de massas vem significativamente substituindo as técnicas de detecção ótica (ultravioleta, arranjo de diodos e fluorescência) e eletroquímica em métodos quantitativos multirresíduos para detecção de macrolídeos em matrizes alimentícias.

Os espectrômetros de massas do tipo QqQ no modo SRM têm se apresentado como os mais sensíveis e, consequentemente, os mais utilizados para a quantificação e confirmação de identidade dos macrolídeos. O uso deste tipo de espectrômetro em outros modos de varredura pode facilitar a identificação de macrolídeos, seus produtos de degradação ou biodegradação e, também, de subprodutos intrínsecos a seus processos de produção.

Apesar de apresentarem repetibilidade fraca e faixas dinâmicas relativamente estreitas, os espectrômetros de massas do tipo QIT ainda podem ser atrativos para quantificar e identificar macrolídeos em matrizes alimentícias devido à sua sensibilidade relativamente alta no modo de varredura completa e, principalmente, à possibilidade de realizar experimentos do tipo $\mathrm{MS}^{\mathrm{n}}$. Os espectrômetros de massas do tipo QLIT reúnem as vantagens do QqQ e do QIT, sem comprometer o desempenho de nenhum deles. Ainda que seu uso na análise de macrolídeos tenha sido raramente reportado, pode-se especular que este tipo de espectrômetro de massas venha a ganhar importância nesta área, devido à sua capacidade de realizar análises nos modos SRM e de varredura do íon produto simultaneamente com boa detectabilidade.

A técnica de UHPLC surgiu mediante os recentes avanços na tecnologia de separação cromatográfica, permitindo o uso de colunas com partículas menores que $2 \mu \mathrm{m}$ que, quando acopladas a um espectrômetro de massas híbrido do tipo QqQ ou QToF, reduzem significativamente o tempo de análise, mantendo a eficiência de separação e melhorando a sensibilidade, em comparação à técnica de LC-MS/MS. 
A aplicação da técnica de UHPLC acoplada a espectrômetros de massas do tipo ToF ou QToF para selecionar, quantificar e identificar macrolídeos e seus produtos de degradação em matrizes complexas vem sendo reconhecida devido às características de rápida separação cromatográfica, alto poder de resolução, capacidade de medição de massa exata e excelente sensibilidade no modo de varredura completa. Há de se reconhecer as limitações destes instrumentos com relação à repetibilidade e faixa dinâmica quando comparados ao QqQ, mas ainda assim eles têm demonstrado boa aplicabilidade na análise de macrolídeos em níveis traço nos alimentos.

A validação dos métodos analíticos para a quantificação de macrolídeos em matrizes alimentícias não somente garante a confiabilidade e a aplicabilidade dos mesmos para fins regulatórios, mas também permite a comparação entre as várias técnicas analíticas disponíveis e a proposição de novas metodologias e técnicas para este fim. As normas regulatórias e os guias para validação têm que estar em constante revisão, de maneira a se adequarem às novas tecnologias disponíveis, melhorando o aproveitamento dos recursos que estes novos instrumentos oferecem.

A espectrometria de massas é uma ferramenta analítica poderosa e os vários tipos de espectrômetros de massas continuam a apresentar papéis complementares na determinação de macrolídeos e compostos relacionados. Os avanços nesta área da química analítica devem melhorar a capacidade de determinar macrolídeos, bem como de outros contaminantes em alimentos, à medida que instrumentos mais avançados, como os QLIT, se tornem mais acessíveis aos laboratórios das agências de fiscalização de segurança alimentar, trazendo benefícios ao comércio internacional de alimentos e à segurança do consumidor.

\section{REFERÊNCIAS}

1. Horie M. Em Chemical analysis for antibiotics used in agriculture; Oka, H.; Nakazawa, H.; Harada, K.; MacNeil, J. D., eds.; AOAC International: Arlington, 1995, chap. 6.

2. Gustafson, R. H.; Bowen, R. E.; J. Appl. Microbiol. 1997, 83, 531.

3. Draisci, R.; Palleschi, L.; Ferretti, E.; Achene, L.; Cecilia, A.; J. Chromatogr., A 2001, 926, 97.

4. Mellon, M.; Benbrook, C.; Benbrook, K. L.; Hogging it: Estimates of antimicrobial abuse in livestock, UCS Publications: Cambridge, 2001, p. 1.

5. Florea, N. F.; Nightingale, C. H.; Diagn. Microbiol. Infect. Dis. 2004, 49, 105.

6. Mathur, S.; Singh, R.; Int. J. Food Microbiol. 2005, 105, 281.

7. Em ref. 4, p. 60.

8. http://www.oie.int/downld/Antimicrobials/OIE_list_antimicrobials.pdf, acessada em Dezembro 2010.

9. Kanfer, I.; Skinner, M. F.; Walker, R. B.; J. Chromatogr., A 1998, 812, 255.

10. Gobel, A.; McArdell, C. S.; Suter, M. J. ; Giger, W.; Anal. Chem. 2004, $76,4756$.

11. Chitneni, S. K.; Govaerts, C.; Adams, E.; van Schepdael, A.; Hoogmartens, J.; J. Chromatogr., A 2004, 1056, 111.

12. Deubel, A.; Fandino, A. S.; Sorgel, F.; Holzgrabe, U.; J. Chromatogr., A 2006, 1136, 39.

13. http://www.emea.europa.eu/htms/vet/mrls/l.htm, acessada em Novembro 2009.

14. Nalda, M. J. N.; Yague, J. L. B.; Gomez, M. T. M.; Sevilla, J. J. J.; del Nozal, J. B.; Pascual, M. H.; J. Sep. Sci. 2006, 29, 405.

15. Kochansky, J.; J. Apic. Res. 2004, 43, 65.

16. Careri, M.; Bianchi, F.; Corradini, C.; J. Chromatogr., A 2002, 970, 3.

17. Wang, J.; Mass Spectrom. Rev. 2009, 28, 50.

18. Wang, J.; Leung, D.; Butterworth, F.; J. Agric. Food Chem. 2005, 53, 1857.
19. Wang, J.; Leung, D.; Rapid Commun. Mass Spectrom. 2007, 21, 3213.

20. Hammel, Y. A.; Mohamed, R.; Gremaud, E.; Lebreton, M. H.; Guy, P. A.; J. Chromatogr., A 2008, 1177, 58.

21. Wang, J.; J. Agric. Food Chem. 2004, 52, 171.

22. Caldow, M.; Stead, S. L.; Day, J.; Sharman, M.; Situ, C.; Elliott, C.; J. Agric. Food Chem. 2005, 53, 7367.

23. Benetti, C.; Piro, R.; Binato, G.; Angeletti, R.; Biancotto, G.; Food Addit. Contam., Part A 2006, 23, 1099.

24. Thompson, T. S.; Noot, D. K.; Calvert, J.; Pernal, S. F.; J. Chromatogr., A 2003, 1020, 241.

25. Lucchetti, D.; Fabrizi, L.; Esposito, A.; Guandalini, E.; Di Pasquale, M.; Coni, E.; J. Agric. Food Chem. 2005, 53, 9689.

26. Cherlet, M.; De Baere, S.; Croubels, S.; De Backer, P.; Anal. Chim. Acta 2002, 473, 167.

27. Heller, D. N.; Nochetto, C. B.; J. Agric. Food Chem. 2004, 52, 6848.

28. Wang, J.; Leung D.; Lenz, S. P.; J. Agric. Food Chem. 2006, 54, 2873.

29. Tang, H. P.; Ho, C.; Lai, S. S.; Rapid Commun. Mass Spectrom. 2006, 20, 2565.

30. Granelli, K.; Branzell, C.; Anal. Chim. Acta 2007, 586, 289.

31. van Poucke, C.; De Keyser, K.; Baltusnikiene, A.; McEvoy, J. D. G.; van Peteghem, C.; Anal. Chim. Acta 2003, 483, 99.

32. van Poucke, C.; Dumoulin, F.; De Keyser, K.; Elliott, C.; van Peteghem, C.; J. Agric. Food Chem. 2004, 52, 2803.

33. Bryskier, A.; J. Antimicrob. Chemother. 1998, 41(Suppl B), 1.

34. Chen, L.; Qin, F.; Ma, Y.; Li, F.; J. Chromatogr., B: Anal. Technol. Biomed. Life Sci. 2007, 855, 255.

35. Bogialli, S.; Di Corcia, A.; Lagana, A.; Mastrantoni, V.; Sergi, M.; Rapid Commun. Mass Spectrom. 2007, 21, 237.

36. Thompson, T. S.; Noot, D. K.; Calvert, J.; Pernal, S. F.; Rapid Commun. Mass Spectrom. 2005, 19, 309.

37. Thompson, T. S.; Pernal, S. F.; Noot, D. K.; Melathopoulos, A. P.; van den Heever, J. P.; Anal. Chim. Acta 2007, 586, 304.

38. Spisso, B. F.; Ferreira, R. G.; Pereira, M. U.; Monteiro, M. A.; Cruz, T. A.; da Costa, R. P.; Lima, A. M. B.; da Nóbrega, A. W.; Anal. Chim. Acta 2010, 682, 82.

39. Tao, Y.; Yu, G.; Chen, D.; Pan, Y.; Liu, Z.; Wei, H.; Peng, D.; Huang, L.; Wang, Y.; Yuan, Z.; J. Chromatogr., B: Anal. Technol. Biomed. Life Sci. 2012, 897, 64.

40. Juan, C.; Moltó, J. C.; Mañes, J.; Font, G.; Food Control 2010, 21, 1703.

41. Maldaner, L.; Jardim, I. C. S. F.; Quim. Nova 2009, 32, 214.

42. Swartz, M. E.; LCGC North Am. 2005, Special Issue, May, 9.

43. Churchwell, M. I.; Twaddle, N. C.; Meeker, L. R.; Doerge, D. R.; J. Chromatogr, B: Anal. Technol. Biomed. Life Sci. 2005, 825, 134.

44. Guillarme, D.; Nguyen, D. T.; Rudaz, S.; Veuthey, J. L.; J. Chromatogr., A 2007, 1149, 20.

45. Codony, R.; Compano, R.; Granados, M.; Garcia-Regueiro, J. A.; Prat, M. D.; J. Chromatogr., A 2002, 59, 131.

46. Gonzalez de la Huebra, M. J.; Vincent, U.; J. Pharm. Biomed. Anal. 2005, 39, 376.

47. Horie, M.; Saito K.; Ishii, R.; Yoshida, T.; Haramaki, Y.; Nakazawa, H.; J. Chromatogr., A 1998, 812, 295.

48. Leroy, P.; Decolin, D.; Nicolas, A.; Archimbault, P.; Analyst (Cambridge, U. K.) 1994, 119, 2743.

49. Sastre Torano, J.; Guchelaar, H. J.; J. Chromatogr, B: Anal. Technol. Biomed. Life Sci. 1998, 720, 89.

50. Edder, P.; Coppex, L.; Cominoli, A.; Corvi, C.; Food Addit. Contam., Part A 2002, 19, 232.

51. Barrett, B.; Borek-Dohalsky, V.; Fejt, P.; Vaingatova, S.; Huclova, J.; Nemec, B.; Jelinek, I.; Anal. Bioanal. Chem. 2005, 383, 210.

52. Chen, B. M.; Liang, Y. Z.; Chen, X.; Liu, S. G.; Deng, F. L.; Zhou P.; J. Pharm. Biomed. Anal. 2006, 42, 480.

53. Hamscher, G.; Limsuwan, S.; Tansakul, N.; Kietzmann, M.; J. Agric. Food Chem. 2006, 54, 9017. 
54. Scheuch, E.; Giessmann, T.; Siegmund, W.; J. Chromatogr., B: Anal. Technol. Biomed. Life Sci. 2006, 844, 84.

55. Scheuch, E.; Spieker, J.; Venner, M.; Siegmund, W.; J. Chromatogr, B: Anal. Technol. Biomed. Life Sci. 2007, 850, 464.

56. Leonard, S.; Ferraro, M.; Adams, E.; Hoogmartens, J.; van Schepdael, A.; Rapid Commun. Mass Spectrom. 2006, 20, 3101.

57. Dubois, M.; Fluchard, D.; Sior, E.; Delahaut, P.; J. Chromatogr., B: Anal. Technol. Biomed. Life Sci. 2001, 753, 189.

58. Draisci, R.; delli Quadri, F.; Achene, L.; Volpe, G.; Palleschi, L.; Palleschi, G.; Analyst (Cambridge, U. K.) 2001, 126, 1942.

59. European Commission; Off. J. Eur. Communities: Legis. 1998, L351, 4.

60. van Poucke, C.; Dumoulin, F.; van Peteghem, C.; Anal. Chim. Acta 2005, 529, 211.

61. Ye, Z.; Weinberg, H. S.; Meyer, M. T.; Anal. Chem. 2007, 79, 1135.

62. Gomez, M. J.; Malato, O.; Ferrer, I.; Aguera, A.; Fernandez-Alba, A. R.; J. Environ. Monit. 2007, 9, 718.

63. Kim, S. C.; Carlson, K.; Environ. Sci. Technol. 2007, 41, 50.

64. Kim, S. C.; Carlson, K.; Anal. Bioanal. Chem. 2007, 387, 1301.

65. Keller, B. O.; Li, L.; J. Am. Soc. Mass Spectrom. 2001, 12, 1055.

66. Chiaradia, M. C.; Collins, C. H. ; Jardim, I. C. S. F.; Quim. Nova 2008, 31,623 .

67. Vessecchi, R.; Lopes, N. P.; Gozzo, F. C.; Dörr, F. A.; Murgu, M.; Lebre, D. T.; Abreu, R.; Bustillos, O. V.; Riveros, J. M. ; Quim. Nova 2011, 34 , 1875.

68. Waters Corporation, Micromass; Q-ToF micro Mass Spectrometer Operator's Guide, Milford, 2002.

69. Hernandez, F.; Sancho, J. V.; Pozo, O. J.; Anal. Bioanal. Chem. 2005, $382,934$.

70. Schlusener, M. P.; Bester, K.; Spiteller, M.; Anal. Bioanal. Chem. 2003, 375, 942.

71. Schlusener, M. P.; Spiteller, M.; Bester, K.; J. Chromatogr., A 2003, 1003, 21.

72. Schlusener, M. P.; Bester, K.; Rapid Commun. Mass Spectrom. 2005, 19, 3269.

73. Rogatsky, E.; Stein, S.; J. Am. Soc. Mass Spectrom. 2005, 16, 1757.

74. Horie, M.; Takegami, H.; Toya, K.; Nakazawa, H.; Anal. Chim. Acta 2003, 492, 187.

75. Sparkman, O. D.; Mass spectrometry desk reference, Global View Publishing: Pittsburgh, 2006, p. 98.

76. http://www.espectrometriademassas.com.br/capitulos/assuntos/assunto. asp? codcapitulo $=8 \&$ codassun to $=63 \&$ numero $=9$, acessada em Setembro 2010.

77. Pico, Y.; Blasco, C.; Font, G.; Mass Spectrom. Rev. 2004, 23, 45.

78. Em ref. 75, p. 99.

79. Hager, J. W.; Yves Le Blanc, J. C.; J. Chromatogr., A 2003, 1020, 3.

80. Soler, C.; Hamilton, B.; Furey, A.; James, K. J.; Manes, J.; Pico, Y.; Rapid Commun. Mass Spectrom. 2006, 20, 2151.

81. Govaerts, C.; Chepkwony, H. K.; Schepdael, A. V.; Roets, E.; Hoogmartens, J.; Rapid Commun. Mass Spectrom. 2000, 14, 878.

82. Hager, J. W.; Rapid Commun. Mass Spectrom. 2002, 16, 512.

83. Hager, J. W.; Yves Le Blanc, J. C.; Rapid Commun. Mass Spectrom. 2003, 17, 1056.

84. Guilhaus, M.; Selby, D.; Mlynski, V.; Mass Spectrom. Rev. 2000, 19, 65.

85. Chernushevich, I. V.; Loboda, A. V.; Thomson, B. A.; J. Mass Spectrom. 2001, 36, 849 .

86. Stolker, A. A.; Niesing, W.; Fuchs, R.; Vreeken, R. J.; Niessen, W. M.; Brinkman, U. A.; Anal. Bioanal. Chem. 2004, 378, 1754.

87. Stolker, A. A.; Niesing, W.; Hogendoorn, E. A.; Versteegh, J. F.; Fuchs, R.; Brinkman U. A.; Anal. Bioanal. Chem. 2004, 378, 955.
88. Bueno, M. J.; Aguera, A.; Gomez, M. J.; Hernando, M. D.; GarciaReyes, J. F.; Fernandez-Alba, A. R.; Anal. Chem. 2007, 79, 9372.

89. Garcia-Reyes, J. F.; Hernando, M. D.; Ferrer, C.; Molina-Diaz, A.; Fernandez-Alba, A. R.; Anal. Chem. 2007, 79, 7308.

90. Petrovic, M.; Gros, M.; Barceló, D.; J. Chromatogr., A 2006, 1124, 68.

91. Petrovic, M.; Barceló, D.; J. Mass Spectrom. 2006, 41, 1259.

92. Barceló, D.; Petrovic, M.; TrAC, Trends Anal. Chem. 2007, 26, 2.

93. Billedeau, S. M. ; Heinze T. M. ; Siitonen, P. H. ; J. Agric. Food Chem. 2003, 51, 1534.

94. Lopes, R. P.; Reyes, R. C.; González, R. R.; Vidal, J. L. M.; Frenich, A. G.; J. Chromatogr., B: Anal. Technol. Biomed. Life Sci. 2012, 895, 39.

95. Luiz, M. M. A.; Vidal, J. L. M.; González, R. R.; Frenich, A. G.; Food Chem. 2012, 132, 2171.

96. Lopes, R. P.; Reyes, R. C.; González, R. R.; Frenich, A. G.; Vidal, J. L. M.; Talanta 2012, 89, 201.

97. Bogialli, S.; Ciampanella, C.; Curini, R.; Di Corcia, A.; Laganà, A.; J. Chromatogr., A 2009, 1216, 6810.

98. Paschoal, J. A. R.; Rath, S.; Airoldi, F. P. S.; Reyes, F. G. R.; Quim. Nova 2008, 31, 1190

99. Thompson, M.; Stephen, L. R.; Wood, R.; Pure Appl. Chem. 2002, 74, 835.

100. Agência Nacional de Vigilância Sanitária, Ministério da Saúde, Brasil; RE no 899, de 29/05/2003, Diário Oficial da União de 02/05/2003.

101. Instituto Nacional de Metrologia, Normalização e Qualidade Industrial (INMETRO); DOQ-CGCRE-008, 2003.

102. Ministério da Agricultura, Pecuária e Abastecimento, Brasil; Diário Oficial da União de 22/07/2009, Seção 1, Página 7.

103. International Standard Organization ; ISO/EC 17025, 1999.

104. International Conference on Harmonization; Validation of Analytical Procedures: Methodology, Q2B, Step 4, Consensus Guideline, November, 1996.

105. European Commission; Off. J. Eur. Communities: Legis. 2002, L221, 8.

106. United States Food and Drug Administration, Center for Drug Evaluation and Research, Center for Veterinary Medicine, Department of Health and Human Services; Guidance for Industry, Bioananalytical Method Validation, May, 2001.

107. United States Food and Drug Administration, Center for Drug Evaluation and Research, Center for Veterinary Medicine, Department of Health and Human Services; Mass Spectrometry for Confirmation of the Identity of Animal Drug Residues, May, 2003.

108. Ribani, M.; Bottoli, C. B. G.; Collins, C. H.; Jardim, I. C. S. F.; Melo, L. F. C.; Quim. Nova 2004, 27, 771.

109. Anadón, A.; Martinez-larranaga, M. R.; Livest. Prod. Sci. 1999, 59, 183.

110. http://www.mrldatabase.com/, acessada em Janeiro 2010.

111. MERCOSUL; MERCOSUL/GMC/RES N $N^{\circ} 54 / 00$, Setembro, 2000.

112. Ministério da Agricultura, Pecuária e Abastecimento, Brasil; Diário Oficial da União de 03/05/2010, Seção 1, Página 27.

113. Agência Nacional de Vigilância Sanitária, Ministério da Saúde, Brasil; Resolução RDC no 253 de 16/09/2003, Diário Oficial da União de 18/09/2003.

114. http://www.m5.ws001.squarestart.ne.jp/foundation/search.html, acessada em Novembro 2010.

115. Ministério da Agricultura, Pecuária e Abastecimento, Brasil; Diário Oficial da União de 16/08/1995, Seção 2, Página 6048.

116. Spisso, B. F.; Nóbrega, A. W.; Marques, M. A. S.; Ciência \& Saúde Coletiva 2009, 14, 2091.

117. ht t p://www.fda.gov/AnimalVeterinary/Products/ ApprovedAnimalDrugProducts, acessada em Novembro 2010. 